\title{
Insights from biochemical reconstitution into the architecture and epigenetic specification of human kinetochores
}

John R. Weir $\left(1, \#,{ }^{*}\right)$, Alex C. Faesen $(1, *)$, Kerstin Klare $(1, *)$, Federica Basilico (1), Josef Fischböck (2), Satyakrishna Pentakota (1), Jenny Keller (1), Arsen Petrovic (1), Marion Pesenti (1), Doro Vogt (1), Sabine Wohlgemuth (1), Franz Herzog (2) \& Andrea Musacchio $(1,3, \#)$

(1) Department of Mechanistic Cell Biology, Max Planck Institute of Molecular Physiology, Otto-Hahn-Straße 11, 44227 Dortmund, Germany

(2) Gene Center Munich, Ludwig-Maximilians-Universität München, Feodor-Lynen-Str. 25, 81377 Munich, Germany

(3) Centre for Medical Biotechnology, Faculty of Biology, University Duisburg-Essen, Universitätsstrasse, 45141 Essen, Germany

* Equal contribution

\# Correspondence: john.weir@mpi-dortmund.mpg.de, andrea.musacchio@mpidortmund.mpg.de

Keywords: kinetochore, centromere, histone, cell division, mitosis, mitotic spindle, synthetic biology, biochemical reconstitution, epigenetics, CCAN, KMN, Mis12, Ndc80, Knl1, Zwint, CENP-A, CENP-B, CENP-C, CENP-H, CENP-K, CENP-I, CENP-L, CENP-M, CENP-N, H3, H4, H2A, H2B, Mis18, M18BP1

Short title: Reconstitution of synthetic kinetochores

Word count: Main text 1520, Abstract 273 
Chromosomes are carriers of the genetic material and their accurate transfer from a mother cell to its two daughters during cell division is of paramount importance for life. Kinetochores are crucial for this process, as they connect chromosomes with microtubules in the mitotic spindle ${ }^{1}$. Kinetochores are multi-subunit complexes that assemble on specialized chromatin domains, the centromeres, whose unique feature is the enrichment of nucleosomes containing the histone H3 variant centromeric protein A (CENP-A) ${ }^{2}$. A group of several additional CENPs, collectively known as constitutive centromere associated network $(\mathrm{CCAN})^{3-6}$, establish the inner kinetochore, whereas a 10 -subunit assembly known as the KMN network creates a microtubule-binding site in the outer kinetochore $^{7,8}$. Interactions between CENP-A and two CCAN subunits, CENP-C and CENP-N, have been previously described ${ }^{9-11}$, but a comprehensive understanding of CCAN organization, of how it contributes to selective recognition of CENP-A, and of how it may contribute to propagate centromere identity through subsequent cell generations has been missing. Here, we use biochemical reconstitution to unveil fundamental principles of kinetochore organization and function. We show that cooperative interactions of a 7-subunit CCAN sub-complex, the CHIKLMN complex, determine binding selectivity for CENP-A over H3-nucleosomes. The CENP-A:CHIKLMN complex binds directly to the KMN network, resulting in a 21-subunit complex that forms a minimal high-affinity linkage between CENP-A nucleosomes and microtubules in vitro. This structural module is related to fungal point kinetochores, which bind a single microtubule. Its convolution with multiple CENP-A may give rise to the regional kinetochores of higher eukaryotes, which bind multiple microtubules. We also note that the specific arrangement of CCAN subunits around CENP-A suggests a model for the propagation of centromere identity through cell division.

The kinetochore is one of the largest and functionally intricate molecular machines of eukaryotic cells ${ }^{12,13}$. It performs two related and essential functions. First, it binds to spindle microtubules to promote the bi-orientation of the sister chromatids in mitosis and meiosis II, and of the homologs in meiosis I. Second, it controls the spindle assembly checkpoint (SAC), a cell cycle checkpoint that prevents chromosome 
segregation prior to completion of bi-orientation, thus ensuring genome stability during cell division ${ }^{1,14}$.

The centromere is the genetic locus, unique to each chromosome, upon which the kinetochore is established $^{2,15}$ (Figure 1a). In most eukaryotes, maintenance of centromere identity does not require specific DNA sequences, but rather relies on epigenetic mechanisms. Crucial for this process is the deposition of new CENP-A at mitotic exit, which repopulates the CENP-A pool after its equal partition to the sister chromatids during DNA replication. Elements of the machinery involved in this reaction have been identified, but a general molecular understanding of this process is missing ${ }^{2,15}$.

Previous genetic and proteomic analyses of human mitotic kinetochores identified up to 100 or more proteins, only a fraction of which are core structural components, while others play accessory regulatory roles. Because CENP-A is considered crucial for the epigenetic specification of centromeres, understanding its recognition by other kinetochore proteins is important. Previous studies established that CENP-C and CENP-N recognise the divergent $\mathrm{C}$-terminal tail and the CATD region of CENP-A, respectively $^{10,11}$ (Extended data Figure 1). Whether CENP-C and CENP-N act in a complex on single or distinct CENP-A nucleosomes, and whether other CCAN subunits contribute to their interactions with CENP-A is not known. To shed light on this problem and on additional functional and structural aspects of kinetochore function, we embarked in a synthetic biology approach aiming to reconstitute human kinetochore function in vitro with purified components (Figure 1b, Extended data Figure 1). Here, we report the main conclusions emerging from this effort.

Similarly to their S. cerevisiae homologs ${ }^{16}$, human CENP-N and CENP-L formed a stoichiometric complex (Extended data Figure 2a). After immobilization on solid phase, CENP-LN interacted preferentially with octameric CENP-A mono-nucleosomes $\left(\mathrm{CENP}-\mathrm{A}^{\mathrm{MN}}\right)$ in comparison to $\mathrm{H} 3$ mono-nucleosomes $\left(\mathrm{H} 3^{\mathrm{MN}}\right.$ ) (Figure 1c). In sizeexclusion chromatography (SEC) experiments, which separate macromolecules based on their size and shape, a recombinant construct encompassing residues 1-544 of CENP-C (CENP-C ${ }^{1-544}$, which embeds the first nucleosome-binding motif of CENP-C, Extended data Figure 1), co-eluted with CENP-A ${ }^{\mathrm{MN}}$ but not with $\mathrm{H} 3^{\mathrm{MN}}$ [both reconstituted on a 145-bp “601” DNA (ref. 17)] (Figure 1d and Extended data Figure 2e-f). SEC also demonstrated that CENP-LN binds directly and strongly to CENP-C ${ }^{1-544}$ (Figure 1e, light blue trace), and directly but more weakly also to the 4-subunit CCAN sub-complex 
CENP-HIKM (ref. 18) (Figure 1e, green trace). Together with our previous demonstration that CENP-C ${ }^{1-544}$ binds CENP-HIKM (ref. 19), these interactions suggest that CENPLN, CENP-HIKM, and CENP-C $\mathrm{C}^{1-544}$ bind in a single complex. SEC readily confirmed this hypothesis (Figure 1e, orange trace). We refer to this 7 -subunit complex as the "CHIKLMN" complex.

Chemical crosslinking coupled with mass spectrometry (XL-MS) ${ }^{20}$ identified an extensive network of interactions of the CHIKLMN subunits with themselves and with CENP$\mathrm{A}^{\mathrm{MN}}$. CENP-C, which may be intrinsically disordered, emerged from this analysis as the backbone of CHIKLMN, as it contacts all other subunits, with the exclusion of histone H2A (Figure 2b, Extended Data Table I). Although the CENP-HIKM complex did not bind CENP-A ${ }^{\mathrm{MN}}$ with affinity sufficient for co-elution in SEC experiments (not shown), we found several crosslinks between them, suggesting close proximity within the CENP$\mathrm{A}^{\mathrm{MN}}$ :CHIKLMN complex.

We asked if the network of interactions linking the CHIKLMN subunits and the CENPA nucleosome correlated with localization co-dependencies in HeLa cells. Individual depletions of CENP-C, CENP-H, CENP-L, or CENP-M by RNA interference (RNAi) led to a near complete disappearance of the other CHIKLMN components from kinetochores during interphase. Significant levels of CENP-A were present on kinetochores at the time of fixation for indirect immunofluorescence, suggesting that the loss of CHIKLMN components is not caused by complete co-depletion of CENP-A, but rather by the co-dependency of CHIKLMN subunits for stable kinetochore recruitment (Figure 2c, Extended Data Figure 3a-b). Collectively, our observations indicate that the CHIKLMN complex forms a cooperative system whose stability depends on reciprocal interactions of its subunits.

The KMN network is made of three sub-complexes, the Knl1 complex (Knl1-C), the Mis12 complex (Mis12-C), and the Ndc80 complex (Ndc80-C). It forms the outer kinetochore and binds microtubules ${ }^{7,8}$ (Figure 1a). After characterizing CHIKLMN as the CENP-A ${ }^{\mathrm{MN}}$ associated complex, we asked if it was also competent to recruit outer kinetochore components. The CENP-A ${ }^{\mathrm{MN}}$ :CHIKLMN complex readily bound to a reconstituted 10-subunit KMN network complex and all components co-eluted from a SEC column, forming a 17-subunit kinetochore complex bound to an octameric CENP$\mathrm{A}^{\mathrm{MN}}$ (Figure 3a, black trace; Figure 3b). Probing the topology of this complex by XL-MS revealed an extensive network of interactions around a hub represented by the Mis12 
complex (Extended Data Figure 4). The latter formed cross-links to several outer kinetochore subunits, as well as to inner kinetochore subunits, including CENP-C, CENP-K, and CENP-N.

We asked if reconstituted kinetochore particles could translocate centromeric chromatin onto microtubules. After immobilizing microtubules on a coverslip, we tested the ability of fluorescently labelled kinetochore components to interact with them (Figure 3c, Extended data Figure 5a). The KMN network bound microtubules in the absence of other components, as expected based on its well-established role as a microtubule receptor at the kinetochore ${ }^{7,8,21}$. Neither CHIKLMN nor CENP-A ${ }^{\mathrm{MN}}$, together or in isolation, decorated microtubules in the absence of the KMN network (Figure 3c). Conversely, when KMN network was added together with the CHIKLMN complex and CENP-A $^{\mathrm{MN}}$, the latter strongly decorated microtubules (Figure 3c), demonstrating that the KMN network and the CHIKLMN complex create a direct bridge between centromeres and microtubules. Only weak binding to microtubules was observed if CENP-A ${ }^{\mathrm{MN}}$ were replaced with $\mathrm{H}^{\mathrm{MN}}$ (Extended data Figure 5b). Addition of CENP$\mathrm{A}^{\mathrm{MN}}$ strongly enhanced the intensity of the KMN on microtubules, suggesting either a stabilisation of binding, or more likely an effect of multi-valency arising from the 2-fold symmetry of the CENP-A ${ }^{\mathrm{MN}}$ (Figure 3c). In this context, we note that the reconstitution of functional kinetochore particles on octameric CENP-A ${ }^{\mathrm{MN}}$ may set a benchmark to resolve an on-going discussion on the actual structure of the CENP-A nucleosome ${ }^{22}$.

The point kinetochore of Saccharomyces cerevisiae consists of a single CENP-A (Cse4) nucleosome associated with proteins that are evolutionarily related to the CCAN subunits of humans ${ }^{13}$ (Figure 4 a). Our finding that the human CCAN subunits and the KMN network form a single, apparently stoichiometric complex on a CENP-A ${ }^{\mathrm{MN}}$ suggests that the human and $S$. cerevisiae kinetochores form a unit of similar architecture. At regional centromeres, which may extend over several megabases of genomic DNA, up to 200 CENP-A nucleosomes intersperse with conventional H3 nucleosomes at an approximate ratio of 1 CENP-A nucleosome over $25 \mathrm{H} 3$ nucleosomes ${ }^{23}$. We therefore propose that kinetochores built on regional centromeres represent the convolution with multiple CENP-A nucleosomes of the structural unit identified by our in vitro reconstitution (Figure 4a).

In metazoans, CENP-A deposition takes place early after cell division and before DNA replication ${ }^{24}$. Doubling of CENP-A levels compensates for the subsequent halving of 
CENP-A content on each sister chromatid during DNA replication, which proceeds without new CENP-A deposition. It is believed that the CENP-A vacancies created during DNA replication become occupied by "placeholder" H3.3 nucleosomes until new CENP-A deposition ${ }^{25}$. The specific topology of the CENP-C protein and of its interactions suggests a molecular mechanism for this process. CENP-C ${ }^{545-943}$, like CENP$\mathrm{C}^{1-544}$, contains a nucleosome-binding element (Extended data Figure 1), reported to bind $\mathrm{MNs}$ with a moderate preference for CENP-A ${ }^{\mathrm{MN}}$ over $\mathrm{H} 3^{\mathrm{MN}}$ [reference 11]. The Cterminal half of CENP-C also interacts directly with the Mis18 complex ${ }^{26}$, which contributes to new CENP-A deposition by recruiting the CENP-A chaperone HJURP to kinetochores early after cell division ${ }^{24}$. In vitro, we found that C-terminal segments of CENP-C interacts with CENP-A ${ }^{\mathrm{MN}}$ but do not recapitulate any of the interactions with CHIKLMN subunits observed with the CENP-C N-terminal segment (Extended Data Figure $6 \mathrm{a}-\mathrm{b}$, summarized in Figure $4 \mathrm{~b})$. We speculate that the C-terminal region of CENP-C marks a second (H3.3) nucleosome, adjacent to the CENP-A ${ }^{\mathrm{MN}}$ :CHIKLMN complex, for replacement with new CENP-A (Figure 4c). This di-nucleosome model, in which CENP-A ${ }^{\mathrm{MN}}-\mathrm{CHIKLMN}$ is viewed as a template for the transformation of a neighbouring $\mathrm{H} 3$ nucleosome, predicts that the number of newly deposited CENP-A molecules may match the number of CENP-A ${ }^{\mathrm{MN}}$ :CHIKLMN complexes already existing within centromeric chromatin. Previous evidence, that CENP-HIKM recruits the FACT complex and the remodelling ATPase Chd1 to kinetochores for new CENP-A deposition, is consistent with this idea ${ }^{27}$. In summary, the model identifies a CENP-A:H3 di-nucleosome structure bound to CHIKLMN as a minimal unit for the deposition of new CENP-A (Figure 4c).

Here we have reported the production of entirely synthetic kinetochores that specifically bind centromeric chromatin while mediating a simultaneous connection to microtubules. Our efforts complement previous studies with kinetochore particles isolated from $S$. cerevisiae $^{28,29}$ or reconstitutions on CENP-A arrays in extracts of Xenopus laevis ${ }^{30}$. Synthetic kinetochores have the potential to drive new inroads into the structural characterization of kinetochore architecture, which remains largely unknown ${ }^{12}$. The manipulation of recombinant kinetochores in vitro may allow gaining molecular insight into crucial kinetochore functions, including the regulation of microtubule binding, of the spindle assembly checkpoint, and of new CENP-A deposition. 


\section{Online content}

Methods, along with additional Extended Data display items, are available in the online version of the paper; references unique to these sections appear only in the online paper.

\section{References}

1 Foley, E. A. \& Kapoor, T. M. Microtubule attachment and spindle assembly checkpoint signalling at the kinetochore. Nature reviews. Molecular cell biology 14, 2537, doi:10.1038/nrm3494 (2013).

2 Fukagawa, T. \& Earnshaw, W. C. The centromere: chromatin foundation for the kinetochore machinery. Developmental cell 30, 496-508, doi:10.1016/j.devcel.2014.08.016 (2014).

3 Izuta, H. et al. Comprehensive analysis of the ICEN (Interphase Centromere Complex) components enriched in the CENP-A chromatin of human cells. Genes Cells 11, 673-684, doi:10.1111/j.1365-2443.2006.00969.x (2006).

4 Foltz, D. R. et al. The human CENP-A centromeric nucleosome-associated complex. Nature cell biology 8, 458-469, doi:10.1038/ncb1397 (2006).

$5 \quad$ Hori, T. et al. CCAN makes multiple contacts with centromeric DNA to provide distinct pathways to the outer kinetochore. Cell 135, 1039-1052, doi:10.1016/j.cell.2008.10.019 (2008).

6 Okada, M. et al. The CENP-H-I complex is required for the efficient incorporation of newly synthesized CENP-A into centromeres. Nature cell biology 8, 446-457, doi:10.1038/ncb1396 (2006).

7 DeLuca, J. G. et al. Kinetochore microtubule dynamics and attachment stability are regulated by Hec1. Cell 127, 969-982, doi:10.1016/j.cell.2006.09.047 (2006).

8 Cheeseman, I. M., Chappie, J. S., Wilson-Kubalek, E. M. \& Desai, A. The conserved KMN network constitutes the core microtubule-binding site of the kinetochore. Cell 127, 983-997, doi:10.1016/j.cell.2006.09.039 (2006).

9 Carroll, C. W., Milks, K. J. \& Straight, A. F. Dual recognition of CENP-A nucleosomes is required for centromere assembly. The Journal of cell biology 189, 1143-1155, doi:10.1083/jcb.201001013 (2010).

10 Carroll, C. W., Silva, M. C., Godek, K. M., Jansen, L. E. \& Straight, A. F. Centromere assembly requires the direct recognition of CENP-A nucleosomes by CENP-N. Nature cell biology 11, 896-902, doi:10.1038/ncb1899 (2009).

11 Kato, H. et al. A conserved mechanism for centromeric nucleosome recognition by centromere protein CENP-C. Science 340, 1110-1113, doi:10.1126/science.1235532 (2013). 
12 Cheeseman, I. M. The kinetochore. Cold Spring Harb Perspect Biol 6, a015826, doi:10.1101/cshperspect.a015826 (2014).

13 Westermann, S. \& Schleiffer, A. Family matters: structural and functional conservation of centromere-associated proteins from yeast to humans. Trends Cell Biol 23, 260-269, doi:10.1016/j.tcb.2013.01.010 (2013).

14 London, N. \& Biggins, S. Signalling dynamics in the spindle checkpoint response. Nature reviews. Molecular cell biology 15, 736-747, doi:10.1038/nrm3888 (2014).

15 Catania, S. \& Allshire, R. C. Anarchic centromeres: deciphering order from apparent chaos. Curr Opin Cell Biol 26, 41-50, doi:10.1016/j.ceb.2013.09.004 (2014).

16 Hinshaw, S. M. \& Harrison, S. C. An Iml3-Chl4 heterodimer links the core centromere to factors required for accurate chromosome segregation. Cell Rep $\mathbf{5}$, 29-36, doi:10.1016/j.celrep.2013.08.036 (2013).

17 Lowary, P. T. \& Widom, J. New DNA sequence rules for high affinity binding to histone octamer and sequence-directed nucleosome positioning. J Mol Biol 276, 19-42, doi:10.1006/jmbi.1997.1494 (1998).

18 Basilico, F. et al. The pseudo GTPase CENP-M drives human kinetochore assembly. Elife 3, e02978, doi:10.7554/eLife.02978 (2014).

19 Klare, K. et al. CENP-C is a blueprint for constitutive centromere-associated network assembly within human kinetochores. The Journal of cell biology 210, 11-22, doi:10.1083/jcb.201412028 (2015).

20 Herzog, F. et al. Structural probing of a protein phosphatase 2A network by chemical cross-linking and mass spectrometry. Science 337, 1348-1352, doi:10.1126/science.1221483 (2012).

21 Ciferri, C. et al. Implications for kinetochore-microtubule attachment from the structure of an engineered Ndc80 complex. Cell 133, 427-439, doi:10.1016/j.cell.2008.03.020 (2008).

22 Westhorpe, F. G. \& Straight, A. F. The split personality of CENP-A nucleosomes. Cell 150, 245-247, doi:10.1016/j.cell.2012.07.003 (2012).

23 Bodor, D. L. et al. The quantitative architecture of centromeric chromatin. Elife 3, e02137, doi:10.7554/eLife.02137 (2014).

24 Jansen, L. E., Black, B. E., Foltz, D. R. \& Cleveland, D. W. Propagation of centromeric chromatin requires exit from mitosis. The Journal of cell biology 176, 795-805, doi:10.1083/jcb.200701066 (2007).

25 Dunleavy, E. M., Almouzni, G. \& Karpen, G. H. H3.3 is deposited at centromeres in $\mathrm{S}$ phase as a placeholder for newly assembled CENP-A in G(1) phase. Nucleus 2, 146-157, doi:10.4161/nucl.2.2.15211 (2011). 
26 Moree, B., Meyer, C. B., Fuller, C. J. \& Straight, A. F. CENP-C recruits M18BP1 to centromeres to promote CENP-A chromatin assembly. The Journal of cell biology 194, 855-871, doi:10.1083/jcb.201106079 (2011).

27 Okada, M., Okawa, K., Isobe, T. \& Fukagawa, T. CENP-H-containing complex facilitates centromere deposition of CENP-A in cooperation with FACT and CHD1. Molecular biology of the cell 20, 3986-3995, doi:10.1091/mbc.E09-01-0065 (2009).

28 Gonen, S. et al. The structure of purified kinetochores reveals multiple microtubule-attachment sites. Nature structural \& molecular biology 19, 925-929, doi:10.1038/nsmb.2358 (2012).

29 Akiyoshi, B. et al. Tension directly stabilizes reconstituted kinetochoremicrotubule attachments. Nature 468, 576-579, doi:10.1038/nature09594 (2010).

30 Guse, A., Carroll, C. W., Moree, B., Fuller, C. J. \& Straight, A. F. In vitro centromere and kinetochore assembly on defined chromatin templates. Nature 477, 354-358, doi:10.1038/nature10379 (2011).

31 Hayashi, T. et al. Mis16 and Mis18 are required for CENP-A loading and histone deacetylation at centromeres. Cell 118, 715-729, doi:10.1016/j.cell.2004.09.002 (2004).

\section{Acknowledgements}

We are very grateful to Fabrizio Martino and Daniela Rhodes for help in setting up MN preparations, to Aaron F. Straight for providing plasmids for expression of CENP-A:H4, and to Kurt A. Davey for plasmids to produce the "601" 145 bp nucleosomal DNA. We thank Giuseppe Ossolengo of the antibody facility at the European Institute of Oncology for help with antibody production, and all other members of the Musacchio laboratory for helpful discussions. A.C.F. is supported by an EMBO long-term fellowship (ALTF 1096-2012) and Marie Curie Intra-European Fellowship (IEF). A.M. acknowledges funding by the European Union's 7th Framework Program Integrated Project (IP) MitoSys, the Horizon 2020 ERC agreement RECEPIANCE, and the DFG's Collaborative Research Centre (CRC) 1093. F.H. is supported F.H. is supported by the European Research Council (MolStruKT StG no. 638218) and by a LMU excellent junior grant. The authors declare no competing financial interests. 


\section{Author Contributions}

J.R.W., K.K., A.C.F. and A.M. designed the experiments. J.R.W, K.K., A.C.F., F.B., J.K., A.P., S.W., M.P. \& S.P. purified proteins. D.V. and F.B. purified nucleosomes. J.R.W. carried out gel filtration experiments. K.K. carried out cell biology experiments. A.C.F. carried out microtubule binding experiments. J.F. and F.H. carried out cross-linking and mass-spec experiments. A.M. coordinated the working team. J.R.W. and A.M. wrote the paper. 


\section{Figure legends}

\section{Figure 1}

\section{Reconstitution of the CHICKLMN complex}

a, Layered organisation of the kinetochore with schematic depiction of sub-complexes. Those in coloured boxes were included in the reconstitution. $\mathbf{b}$, Coomassie-stained SDSPAGE of recombinant proteins used in this study. c, CENP-NL binds preferentially to CENP-A over H3. GST-tagged CENP-L in complex with CENP-N on GSH-sepharose beads was combined with either CENP-A ${ }^{\mathrm{MN}}$ or $\mathrm{H} 3^{\mathrm{MN}}$. d, CENP-C $\mathrm{C}^{1-544}$ binds preferentially to CENP-A ${ }^{\mathrm{MN}}$ over $\mathrm{H} 3^{\mathrm{MN}}$. SEC elution profiles of CENP-C ${ }^{1-544}$ (red trace), CENP-C ${ }^{1-544}$ mixed to CENP-A ${ }^{\mathrm{MN}}$ (purple), and CENP-C ${ }^{1-544}$ mixed to H3 ${ }^{\mathrm{MN}}$ (grey). Shift in the elution profile indicate binding of CENP-C ${ }^{1-544}$ to CENP-A ${ }^{\mathrm{MN}}$. e) CENP-NL (dark blue trace) binds CENP-C (light blue trace), and binds CENP-HIKM (light blue trace). These interactions are compatible and lead to formation of a 7-subunit 'CHIKLMN' complex (orange trace),

\section{Figure 2}

\section{Selective cooperative binding of CHIKLMN to CENP-A mononucleosomes}

a, CHIKLMN complex (red trace) binds to CENP-A (green trace) but not H3 (blue trace). The composition of the CENP-A ${ }^{\mathrm{MN}}$ :CHIKLMN complex was confirmed by Western blotting of several subunits. $\mathbf{b}$, topology of the CENP-A ${ }^{\mathrm{MN}}$ :CHIKLMN complex. Chemical cross-linking with DSS, followed by mass spectrometry, revealed a network of cross-linked peptides. Intra protein cross-links are shown as red lines, intrasubcomplex cross-links are shown as orange lines, inter-subcomplex cross-links are shown as black lines. Proteins are coloured according to sub-complex (CENP-C, red; CENP-NL, blue; CENP-HIKM, green; CENP-A ${ }^{\mathrm{MN}}$, purple.) c, cooperative localization of CHIKLMN to kinetochores. Quantification of kinetochore levels of CENP-C (red bars), CENP-HK (green bars), and CENP-A (purple) measured by immunofluorescence (IF) in control HeLa cells (left) or after depletion of the indicated CCAN subunits by siRNAs. Localisations of CENP-C and CENP-HK are significantly perturbed, despite relatively high residual CENP-A levels. Representative IF images and number of cells used are shown in Extended Data Figure 3. 


\section{Figure 3}

\section{$K M N$ and $C H I K L M N$ connect $C E N P-A$ to microtubules}

a, the CHIKLMN:CENP-A ${ }^{\mathrm{MN}}$ complex (green trace) and the KMN (yellow trace) were mixed, run on a Superose 6 SEC column (black trace), and analysed by SDS-PAGE. All 17 components of the kinetochore and the 4 subunits of the CENP-A ${ }^{\mathrm{MN}}$ shift together. b, analysis of peak fraction by Coomassie staining and WB demonstrates co-elution of all subunits. c, microtubule binding assay. Rhodamine-labelled microtubules (red channel) were tethered to glass coverslips and incubated in the presence of GFP-KMN (green), Alexa-488 labelled CHIKLMN (blue), or Alexa-647 labelled CENP-A ${ }^{\mathrm{MN}}$ (purple), and combinations thereof.

\section{Figure 4}

\section{Centromere and kinetochore assembly and propagation}

a, similar subunit composition suggests conservation of a structural module that is used only once at "point" centromeres/kinetochores, which bind a single microtubule, and that is instead repeated several times at "regional" centromeres/kinetochores, which bind multiple microtubules ${ }^{13}$. As little as 1 nucleosome in 25 may contain CENP-A at centromeres $^{23}$. b, matrix of intra-kinetochore interactions. An observed physical interaction is highlighted in green, and lack of interaction is shown in red. c, a dinucleosome model of kinetochore assembly and new CENP-A deposition. The Nterminal region of CENP-C (exemplified by CENP-C ${ }^{1-544}$ ) binds the $\mathrm{KMN}$, the CHIKLMN, and CENP-A ${ }^{\mathrm{MN}}$. The C-terminal region of CENP-C (exemplified by CENP-C $\mathrm{C}^{545-943}$ ) does not bind core kinetochore component (this study) but interacts with CENP-A loading machinery, including the Mis18 complex, which in turn recruits the CENP-A chaperone HJURP ${ }^{26,31}$. Each half of CENP-C contains a nucleosome-binding motif, and has therefore potential to interact with two adjacent nucleosomes. After DNA replication, when CENP-A levels are halved, CENP-A is replaced with $\mathrm{H} 3$ (H3.3, references 24,25), and the C-terminal region of CENP-C binds to it, "marking" the nucleosome for future exchange with CENP-A. After mitosis, the C-terminal region of CENP-C contributes to recruit machinery that replaces H3 with CENP-A. Thus, the Cterminal region of CENP-C may bind to a nucleosome that "toggles" between H3 (in 
mitosis) and CENP-A (in interphase). 
a

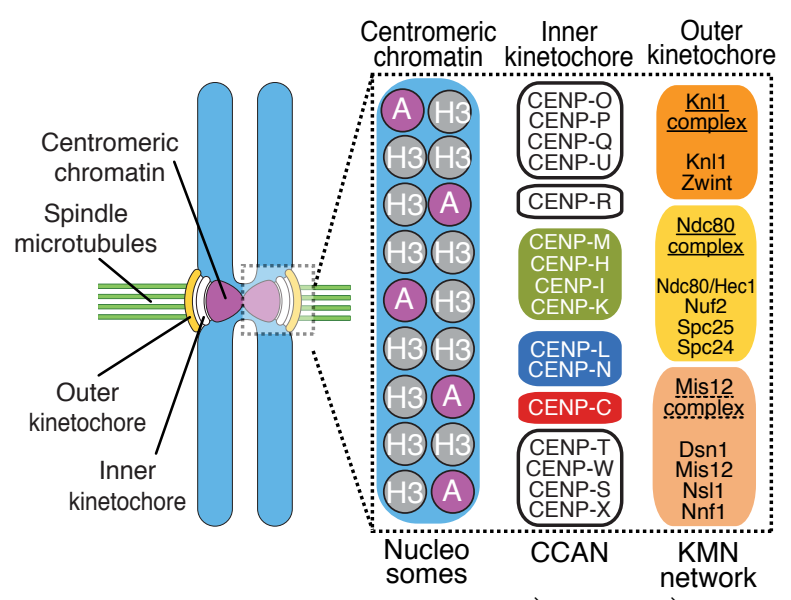

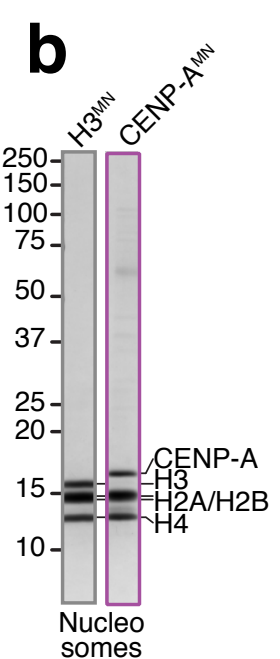
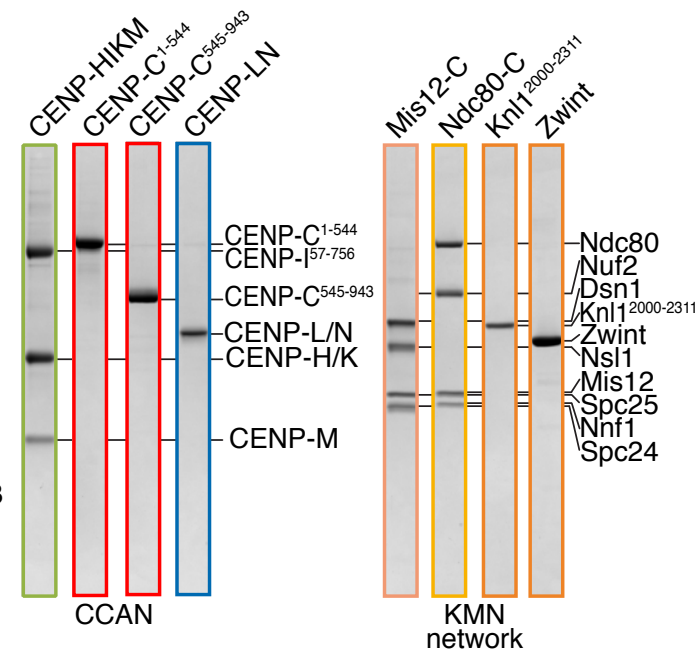
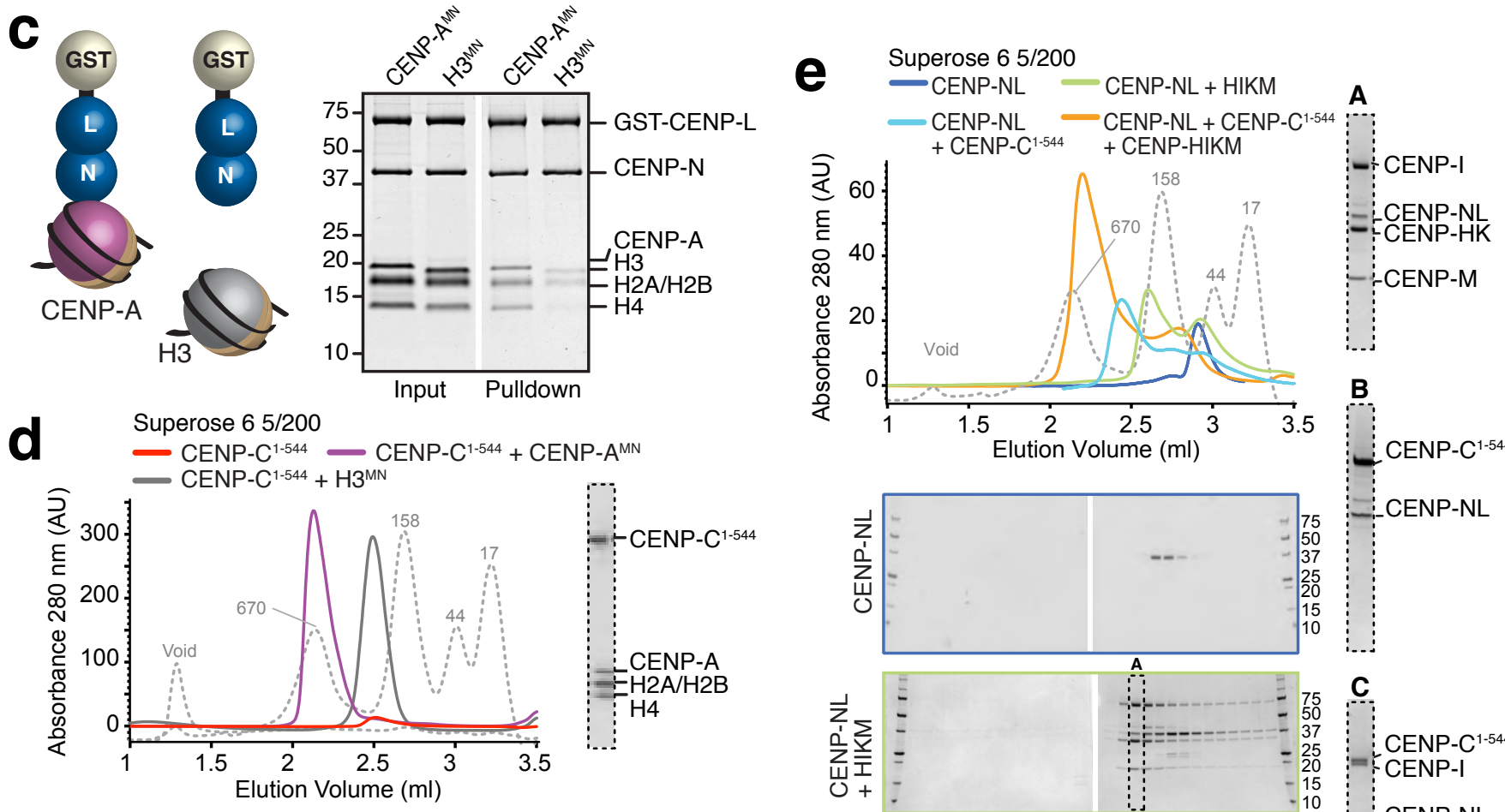

CENP-C ${ }^{1-544}$
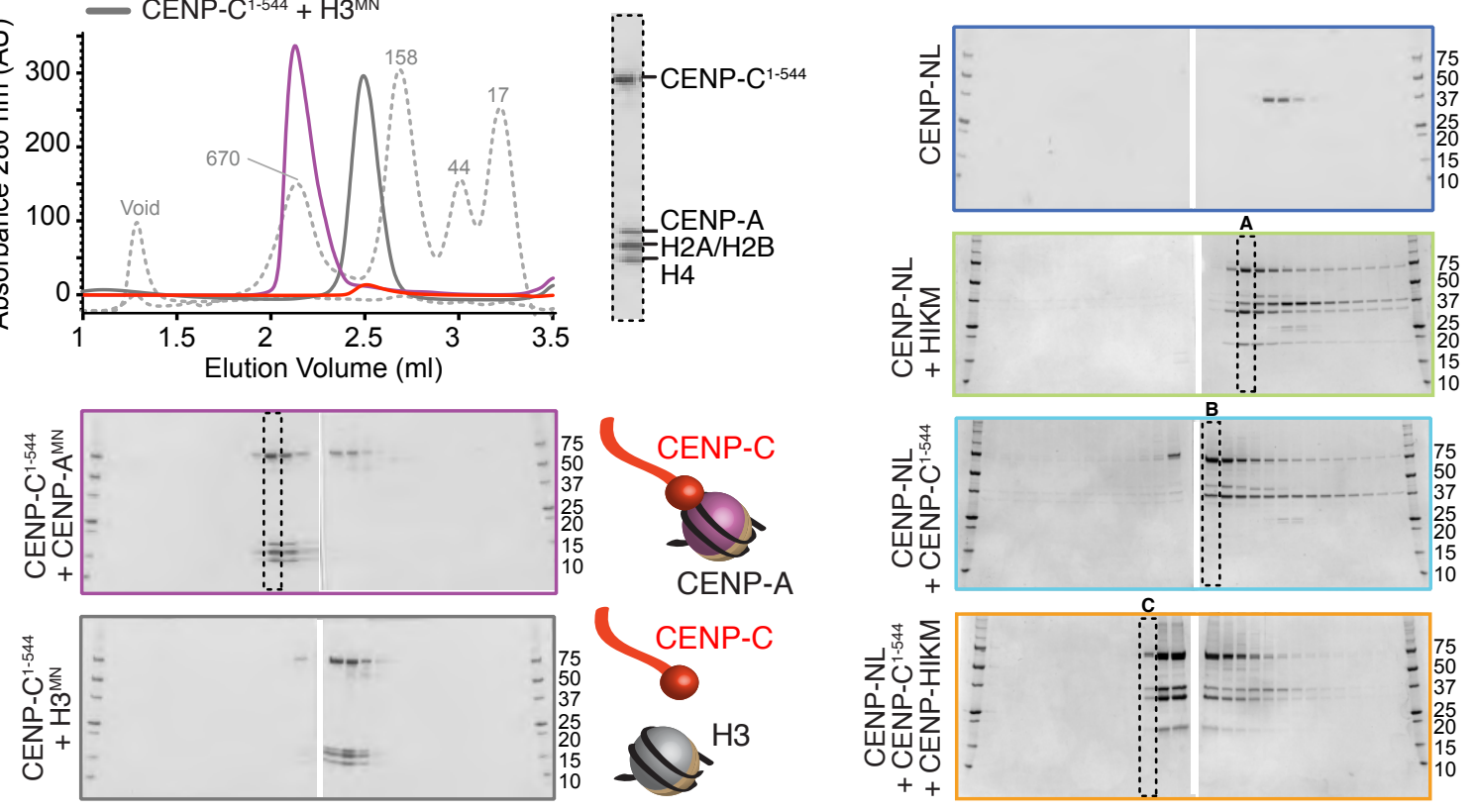

CENP-NL

CENP-C ${ }^{1-54}$

CENP-I

CENP-NL

-CENP-M

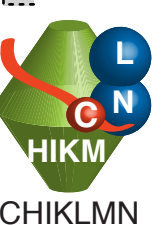

Weir et al.

Figure 1 

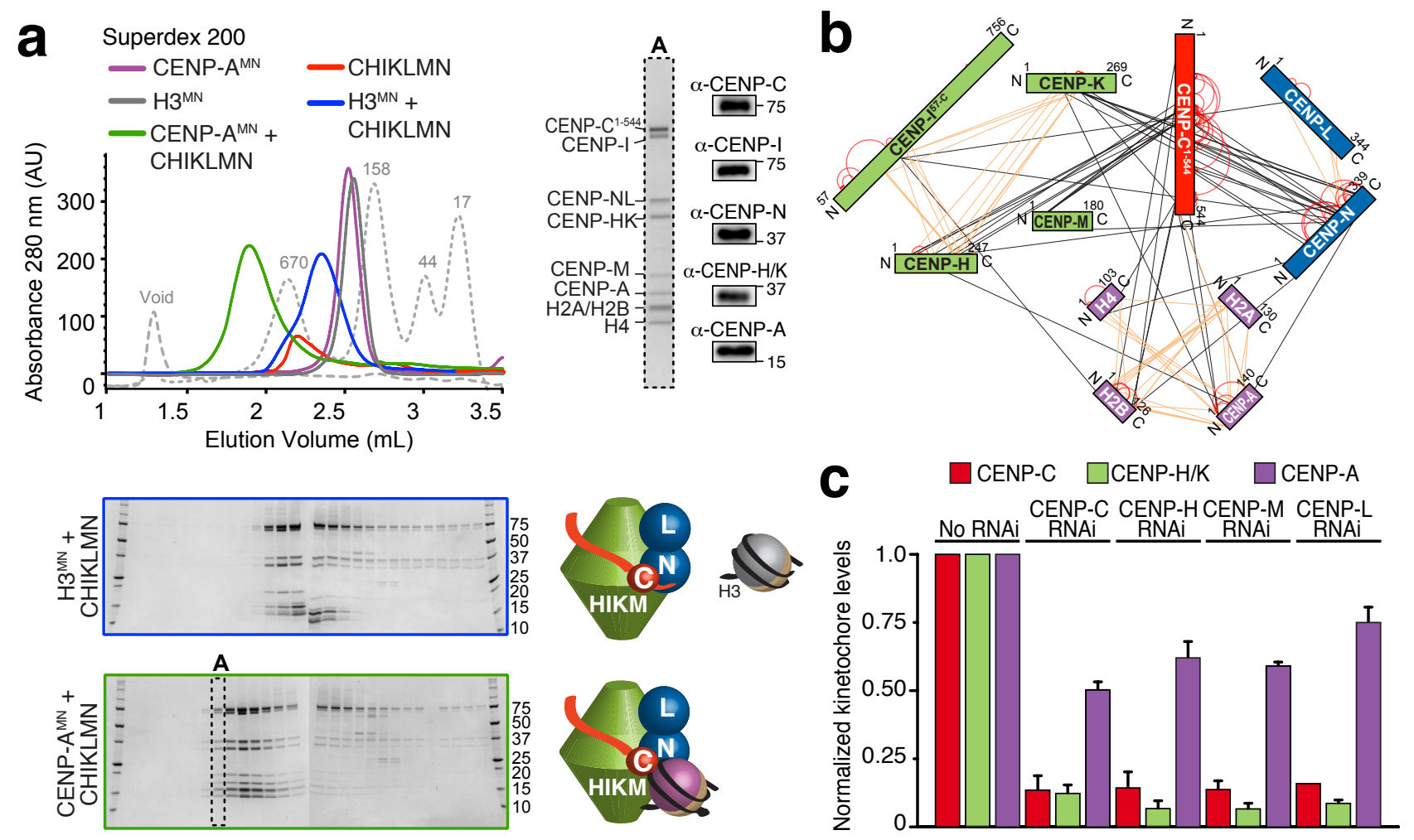

Weir et al.

Figure 2 


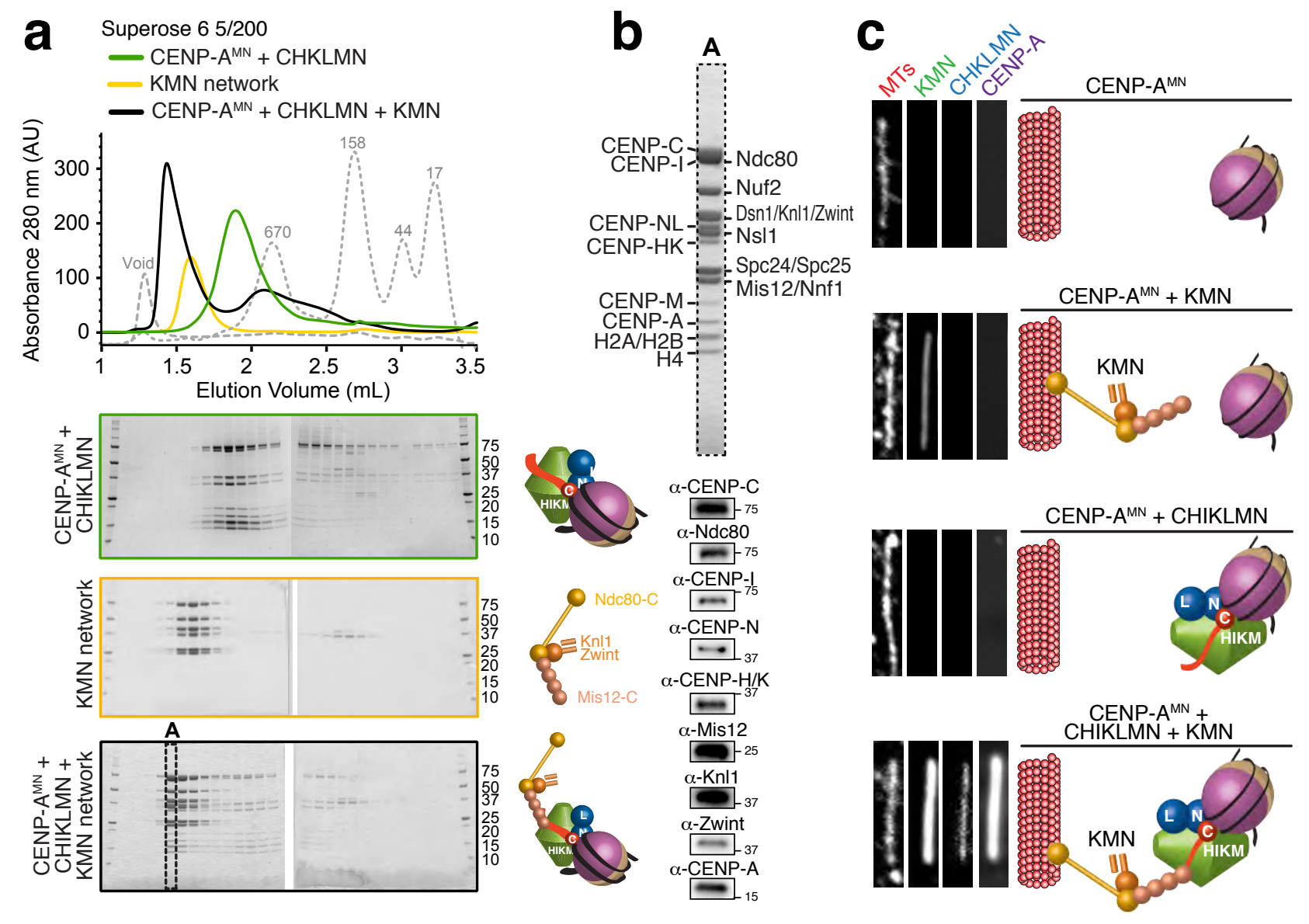

Weir et al.

Figure 3 


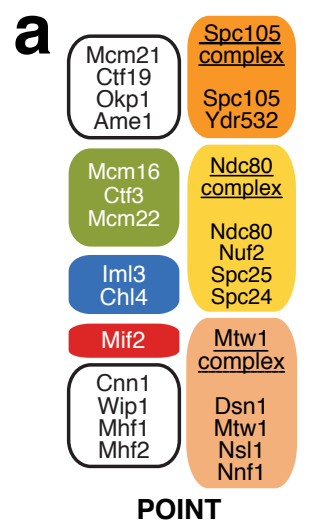

(S. cerevisiae)

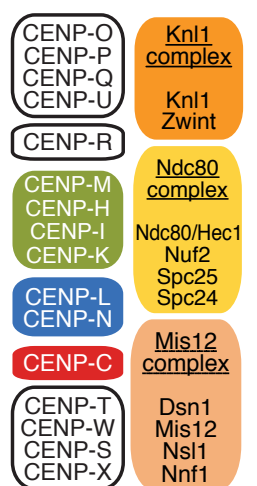

REGIONAL
Homo sapiens

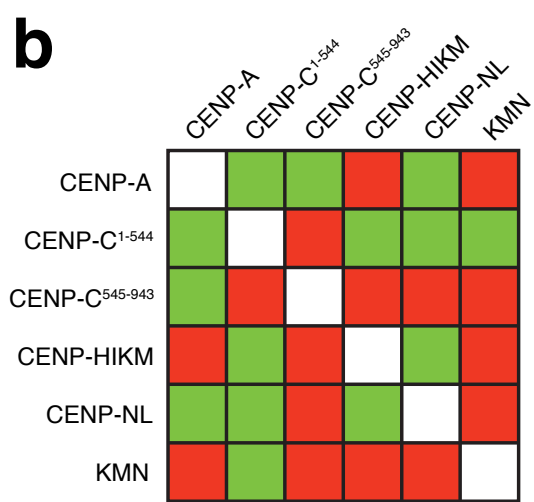

\section{C}

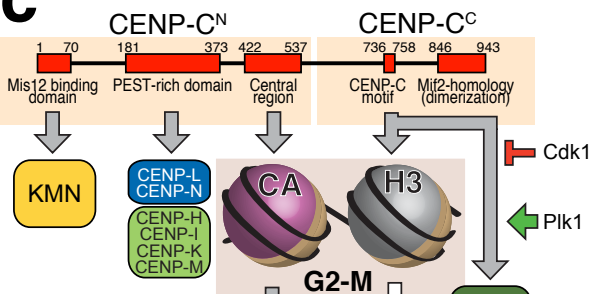

+ NPM1, RbAp46,

RbAp48, RSF

AND-1,

Centralspindlin,
unknown factors

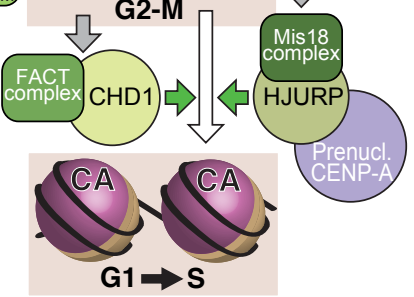

Weir et al.

Figure 4 


\section{Methods Summary}

Production of recombinant proteins CENP-NL was produced as a GST fusion construct from insect cells using a baculovirus expression system using the MultiBac system $^{1}$. Specifically, a coding sequence expressing 3C cleavable GST-tagged CENP-L was sub-cloned into MCS2, and the coding sequence of CENP-N was sub-cloned into MCS1 of pFL. Bacmid was then produced from EMBacY cells ${ }^{1}$, and subsequently used to transfect Sf9 cells and produce baculovirus. Baculovirus was amplified through three rounds of amplification and used to infect Tnao38 cells. ${ }^{2}$. Cells infected with the GSTCENP-L/CENP-N virus were cultured for 72 hours before harvesting. Cells were washed and resuspended in lysis buffer (50 mM Na-HEPES, $300 \mathrm{mM} \mathrm{NaCl}, 10 \%$ glycerol, $4 \mathrm{mM}$ 2-mercaptoethanol, $1 \mathrm{mM} \mathrm{MgCl}_{2} \mathrm{pH}$ 7.5). Resuspended cells were lysed by sonication in the presence of Benzonase before clearance at $100,000 \mathrm{~g}$ at $4^{\circ} \mathrm{C}$ for 1 hour. Cleared lysate was passed over GSH-Sepharose, before extensive washing with lysis buffer. GST-CENP-L/CENP-N complex was then eluted in lysis buffer $+20 \mathrm{mM}$ reduced glutathione. Eluted protein was concentrated in a $30 \mathrm{kDa}$ Amicon-Ultra-15 Centrifugal Filter (Millipore) in the presence of GST-tagged 3C protease. Concentrated protein was then loaded onto a Superdex 200 16/600 column equilibrated in $20 \mathrm{mM} \mathrm{Na}$ HEPES pH 7.5, $300 \mathrm{mM} \mathrm{NaCl}, 2.5 \%$ glycerol, pH 7.5. A 5 mL GSH-Sepharose FF column was connected in series after the Superdex 200 column to trap GST, un-cut GST-CENP-L/CENP-N and GST-tagged 3C protease. Peak fractions corresponding to CENP-L/CENP-N were collected and again concentrated in a $30 \mathrm{kDa}$ MWCO concentrator to approximately $50-100 \mu \mathrm{M}$ prior to being flash frozen in liquid $\mathrm{N}_{2}$ and storage at $-80^{\circ} \mathrm{C}$. Other proteins were purified as described previously \{Basilico:2014uc; Klare:2015co; Petrovic:2014cx; Tachiwana, 2015 \#561\}.

H3 containing MNs Plasmids for the production of Xenopus laevis H2A, H2B, H3 and H4 histones were a kind gift of Prof. Daniela Rhodes. Xenopus laevis histone expression and purification, refolding of histone octamers or $\mathrm{H} 2 \mathrm{~A}: \mathrm{H} 2 \mathrm{~B}$ dimers, and reconstitution of $\mathrm{H} 3$ containing mononucleosomes were performed precisely as described ${ }^{3}$. Plasmids for the production of the "601" 145-bp DNA were a kind gift of Prof. Curt A. Davey at the Nanyang Technological University in Singapore. DNA production was performed as described $^{3}$ with no modifications. 
CENP-A containing MNs Plasmids for the production of human CENP-A:H4 histone tetramer were a kind gift of Prof. Aaron F. Straight's laboratory at Stanford University. Preparations of CENP-A-containing MNs were carried out precisely as described ${ }^{4}$.

Analytical SEC analysis Analytical size exclusion chromatography was carried out on a custom made Superose $65 / 200$ in a buffer containing $20 \mathrm{mM}$ HEPES, $300 \mathrm{mM} \mathrm{NaCl}$, $2.5 \%$ glycerol, $2 \mathrm{mM}$ TCEP, pH 7.5 on an ÄKTAmicro system. As indicated, the following additional columns were used: Superdex 200 5/150 Increase and Superose 6 5/150. All samples were eluted under isocratic conditions at $4^{\circ} \mathrm{C}$ in SEC buffer $(20 \mathrm{mM}$ Hepes $\mathrm{pH}$ 7.5, $300 \mathrm{mM} \mathrm{NaCl}, 2.5 \%$ Glycerol, $2 \mathrm{mM}$ TCEP) at a flow rate of 0.2 $\mathrm{ml} / \mathrm{min}$. Elution of proteins was monitored at $280 \mathrm{~nm}$. $100 \mu \mathrm{l}$ fractions were collected and analysed by SDS-PAGE and Coomassie blue staining. To detect the formation of a complex, proteins were mixed at the indicated concentrations in $50 \mu$, incubated for at least $2 \mathrm{hr}$ on ice and then subjected to SEC.

Kinetochore microtubule binding assay Cover slips and glass slides were cleaned by sonication in isopropanol and $1 \mathrm{M} \mathrm{KOH}$ or $1 \%$ Hellmanex and $70 \%$ ethanol, respectively. After functionalization of cover slips with $5 \%$ biotinylated poly-L-lysinePEG for $30 \mathrm{~min}$, flow cells were created with a volume of 10-15 $\mu \mathrm{L}$. Flow cells were passivated with $1 \%$ pluronic F-127 for $1 \mathrm{~h}$ and coated with avidin for 30-45 min. After incubation with $10 \mathrm{nM}$ microtubules $(10 \%$ biotinylated, $10 \%$ Rhodamine labeled, Cytoskeleton, Inc., polymerized according to manufacturer's instructions) for 10-20 min. Proteins (400 nM) were added in $80 \mathrm{mM}$ Pipes (pH6.8), $125 \mathrm{mM} \mathrm{KCl}, 1 \mathrm{mM}$ EGTA, 1 $\mathrm{mM} \mathrm{MgCl}_{2}$ and $20 \mu \mathrm{M}$ Taxol). Flow cells were sealed with wax and imaged with spinning disk confocal microscopy on a $3 \mathrm{i}$ Marianas system (Intelligent Imaging Innovations, Göttingen, Germany) equipped with Axio Observer Z1 microscope (Zeiss, Oberkochen, Germany), a CSU-X1 confocal scanner unit (Yokogawa Electric Corporation, Tokyo, Japan), Plan-Apochromat 100x/1.4NA DIC oil objective (Zeiss), Orca Flash 4.0 sCMOS Camera (Hamamatsu, Hamamatsu City, Japan) and controlled by Slidebook Software 6.0 (Intelligent Imaging Innovations). Images were acquired as z- sections at $0.27 \mu \mathrm{m}$ and maximal intensity projections were made with Slidebook Software 6.0 (Intelligent Imaging Innovations).

GST-pulldown assays GST pulldown experiments were performed using preblocked GSH Sepharose beads in pulldown buffer $(10 \mathrm{mM}$ Hepes pH 7.5, $200 \mathrm{mM} \mathrm{NaCl}, 0.05 \%$ Triton, $2.5 \%$ Glycerol, $1 \mathrm{mM}$ TCEP). GST-CENP-NL as bait at a $1 \mu \mathrm{M}$ concentration 
was incubated with MNs as prey at a $3 \mu \mathrm{M}$ concentration. The bait was loaded to $12 \mu \mathrm{l}$ preblocked beads, before the prey was added. At the same time, $1 \mu \mathrm{g}$ of each protein was added into Laemmli sample loading buffer for the input gel. The reaction volume was topped up to $40 \mu \mathrm{l}$ with buffer and incubated at $4^{\circ} \mathrm{C}$ for $1 \mathrm{~h}$ under gentle rotation. Beads were spun down at $500 \mathrm{~g}$ for 3 minutes. The supernatant was removed and beads washed twice with $250 \mu \mathrm{l}$ buffer. Supernatant was removed completely, samples boiled in $15 \mu \mathrm{l}$ Laemmli sample loading buffer and run on a $14 \%$ SDS-PAGE gel. Bands were visualized with Commassie brilliant blue staining. Preblocking of GSH sepharose beads $750 \mu \mathrm{l}$ of GSH Sepharose beads were washed twice with $1 \mathrm{ml}$ washing buffer $(20 \mathrm{mM}$ Hepes $\mathrm{pH} 7.5,200 \mathrm{mM} \mathrm{NaCl})$ and incubated in $1 \mathrm{ml}$ blocking buffer $(20 \mathrm{mM}$ Hepes $\mathrm{pH}$ $7.5,500 \mathrm{mM} \mathrm{NaCl}, 500 \mu \mathrm{g} / \mu \mathrm{l} \mathrm{BSA})$ over night at $4^{\circ} \mathrm{C}$ rotating. Beads were washed 5 times with $1 \mathrm{ml}$ washing buffer and resuspended in $500 \mu \mathrm{l}$ washing buffer to have a $50 / 50$ slurry of beads and buffer.

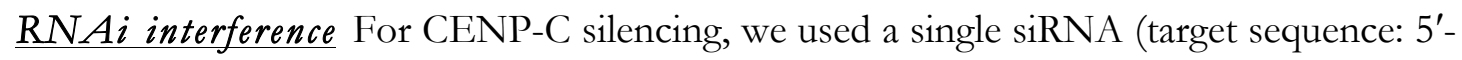
GGAUCAUCUCA- GAAUAGAA-3' obtained from Sigma-Aldrich), targeting the coding region of endogenous CENP-C mRNA. For an efficient depletion, siRNA for CENP-C was transfected at a concentration of $60 \mathrm{nM}$ for $72 \mathrm{~h}$. For CENP-A silencing a single siRNA (target sequence: 5'-CACAGUCGGCGGAGACAAGTT-3' obtained from Dharmacon) was used, as previously published ${ }^{5}$. To obtain an efficient depletion of CENP-A, $100 \mathrm{nM}$ siRNA was transfected for $120 \mathrm{~h}$. For CENP-M silencing, we used a combination of three siRNA duplexes (target sequences: 5'ACAAAAGGUCUGUGGCUAA-3'; 5'-UUAAGCAGCUGGCGUGUUA-3'; 5'GUGCUGACUCCAUAAACAU-3'; purchased from Thermo Scientific, Carlsbad, CA) targeting the 3'-UTR of endogenous CENP-M. CENP-M siRNA duplexes were used at $20 \mathrm{nM}$ each for $72 \mathrm{~h}$ as published ${ }^{6}$. For CENP-H a single siRNA (target sequence: $5^{\text {'- }}$ CUAGUGUCUCAUGGAUAA-3' obtained from Dharmacon) targeting the coding region of endogenous CENP-H mRNA was used at $100 \mathrm{nM}$ for $72 \mathrm{~h}$. For CENP-L a single siRNA (target sequence: 5'- UUUAUCAGCCACAAGAUUA-3' obtained from Dharmacon) targeting the coding region of endogenous CENP-L was used at $100 \mathrm{nM}$ for $72 \mathrm{~h}$. Transfections of RNAi were performed with HyPerFect (QIAGEN) according to the manufacturer's instructions.

Mammalian plasmids Constructs were created by cDNA subcloning in pcDNA5/ FRT/TO-mCherry-IRES vector, a modified version of pcDNA5/FRT/TO vector (Invitrogen). pcDNA5/FRT/TO vector (Invitrogen) is a tetracycline-inducible 
expression vector designed for use with the Flp-In T-REx system. It carries a hybrid human cytomegalovirus/TetO2 promoter for high-level, tetracycline-regulated expression of the target gene. The control plasmid for mCherry expression was created by PCR amplifying the mCherry sequence and cloning it into the pcDNA5/FRT/TO vector previously modified to carry an internal ribosomal entry site (IRES) sequence to obtain the pcDNA5/FRT/TO mCherry-IRES vector. All plasmids used in the study for mammalian expression were derived from the pCDNA5/FRT/TO-mCherry-IRES and used for genomic integration and expression of human CENP-N o -L proteins. To create all N-terminally tagged mCherry fusions, we amplified CENP-N or CENP-L fragments by PCR from human cDNA and subcloned them in frame with the mCherry tag into the pcDNA5/FRT/TO mCherry-IRES vector using the restriction sites BamHI and XhoI.

Cell culture and transfection Parental Flp-In T-REx HeLa cells used to generate stable doxycycline-inducible cell lines were a gift from Stephen Taylor (University of Manchester, Manchester, England, UK). They were grown at $37^{\circ} \mathrm{C}$ in the presence of $5 \%$ CO2 in Dulbecco's Modified Eagle's Medium (DMEM; PAN Biotech) supplemented with $10 \%$ TET-free Fetal Bovine Serum (Invitrogen) and $2 \mathrm{mM} \mathrm{L-glutamine} \mathrm{(PAN-}$ Biotech). Flp-In T-REx HeLa cells ${ }^{7}$ and maintained in DMEM supplemented with $10 \%$ tetracycline-free FBS, $2 \mathrm{mM}$ L-glutamine, $250 \mu \mathrm{g} / \mathrm{ml}$ hygromycin (Invitrogen, Carlsbad, CA) and $4 \mu \mathrm{g} / \mathrm{ml}$ blastidicin (Invitrogen, Carlsbad, CA). GFP-CENP-C fusions were expressed by addition of $25 \mathrm{ng} / \mathrm{ml}$ doxycycline (Sigma, St. Louis, MO) for 24 or $48 \mathrm{hr}$. For CENP-C silencing, we used a single siRNA (target sequence: 5'GGAUCAUCUCAGAAUAGAA-3' from Sigma, St. Louis, MO), targeting the coding region of endogenous CENP-C mRNA. Transfections were performed with HyPerFect (Qiagen) according to the manufacturer's instructions. To obtain an efficient depletion of CENP-C, $60 \mathrm{nM}$ siRNA was transfected 3 times within $72 \mathrm{hr}$. In the last $24 \mathrm{hr} 25 \mathrm{ng} / \mathrm{ml}$ doxycycline was added to induce GFP-CENP-C construct expression. The siRNA did not effect expression of GFP-CENP. Phenotypes were analysed $96 \mathrm{hr}$ after first siRNA addition and protein depletion was monitored by Western blotting or immunofluorescence.

Immunoblotting RNAi depleted cells for various CCAN components were harvested by trypsinisation and lysed by incubation in lysis buffer (75 mM HEPES pH 7.5, $150 \mathrm{mM}$ $\mathrm{KCl}, 1.5 \mathrm{mM}$ EGTA, $1.5 \mathrm{mM} \mathrm{MgCl} 2,10 \%$ glycerol, 0.075\% NP-40, $90 \mathrm{U} / \mathrm{ml}$ benzonase (Sigma), protease inhibitor cocktail (Serva) at $4^{\circ} \mathrm{C}$ for $15 \mathrm{~min}$ followed by sonication and 
centrifugation. Cleared lysate was washed with lysis buffer, resuspended in Laemmli sample buffer, boiled and analyzed by western blotting using 12\% NuPAGE gels (Life technologies). The following antibodies were used: anti-Vinculin (mouse monoclonal, clone hVIN-1; 1:15000; Sigma-Aldrich, V9131), anti $\alpha$-tubulin (mouse monoclonal, Sigma-Aldrich T9026), anti-CENP-C [rabbit polyclonal antibody SI410 raised against residues 23-410 of human CENP-C; 1:1200; reference ${ }^{8}$ ], anti-CENP-HK (rabbit polyclonal antibody SI0930 raised against the full length human CENP-HK complex; 1:1000), anti-CENP-M (rabbit polyclonal antibody raised against the full length human CENP-M), anti-CENP-L (rabbit polyclonal, Acries antibodies 17007-1-AP). Secondary antibodies were affinity purified anti-mouse (Amersham, part of GE Healthcare), antirabbit or anti-mouse (Amersham) conjugated to horseradish peroxidase (1:10000). After incubation with ECL western blotting system (GE Healthcare), images were acquired with ChemiDoc ${ }^{\text {TM }}$ MP System (BioRad). Levels were adjusted with ImageJ and Photoshop and images were cropped accordingly

Immunofluorescence and quantification Flp-In T-REx HeLa cells (parental or mCherry-CENP$\mathrm{L}$ inducible) were grown on coverslips pre-coated with $0.01 \%$ poly-L-Lysine (Sigma). Cells were fixed with PBS/PHEM-paraformaldehyde $4 \%$ followed by permeabilisation with PBS/PHEM-Triton 0.5\%. The following antibodies were used for immunostaining: CREST/anti-centromere antibodies (human auto-immune serum, 1:100; Antibodies Inc., Davis, CA), .), anti-CENP-C (SI410; 1:1,000, or the directly Alexa488 conjugated form of this antibody 1:400), anti-CENP-A mouse monoclonal (Gene Tex GTX13939, 1:500) anti-CENP-HK (SI0930; 1:800 or the Alexa488 directly conjugated form of this antibody 1:800). Rodamine Red-conjugated, DyLight405-conjugated secondary antibodies were purchased from Jackson ImmunoResearch Laboratories, West Grove, PA. Alexa Fluor 647-labeled secondary antibodies were from Invitrogen. Coverslips were mounted with Mowiol mounting media (Calbiochem). All experiments were imaged at room temperature using the spinning disk confocal microscopy of a 3i Marianas system (Intelligent Imaging Innovations, Denver, CO) equipped with an Axio Observer Z1 microscope (Zeiss, Oberkochen, Germany), a CSU-X1 confocal scanner unit (Yokogawa Electric Corporation, Tokyo, Japan), Plan-Apochromat 63x or 100x/1.4NA objectives (Zeiss) and Orca Flash 4.0 sCMOS Camera (Hamamatsu, Hamamatsu City, Japan) and converted into maximal intensity projections TIFF files for illustrative purposes. Quantification of kinetochore signals was performed on unmodified Z-series images using Imaris 7.3.4 software (Bitplane, Zurich, Switzerland). After background 
subtraction, all signals were normalized to CREST where indicated and values obtained for control cells were set to 1 . In some cases (e.g. CENP-L RNAi treatment, the levels of CREST were decreased below detection limit, probably to loss of proteins CREST antibody recognizes). In these cases protein levels were only substracted by the background and total proteins levels were set in relation to the untreated control cells. Quantifications are based on three independent experiments where 5 to 10 cells were analysed.

Chemical cross-linking and mass spectrometry Cross-linking analysis of CENP$\mathrm{A}^{\mathrm{MN}}$ :CHIKLMN:KMN complex was performed with an equimolar mixture of light and heavy-labeled (deuterated) bis[sulfosuccinimidyl] suberate $\left(B S 3-\mathrm{d}_{0} / \mathrm{d}_{12}\right.$, Creative Molecules). The complex was incubated with $0.8 \mathrm{mM} \mathrm{BS} 3$ for $30 \mathrm{~min}$ at $30^{\circ} \mathrm{C}$ and the crosslinking reaction was quenched by adding ammonium bicarbonate to a final concentration of $100 \mathrm{mM}$. Digestion with lysyl enodpeptidase (Wako) was performed at $35^{\circ} \mathrm{C}, 6 \mathrm{M}$ Urea for $2 \mathrm{~h}$ (at enzyme-substrate ratio of 1:50 w/w) and was followed by a second digestion with trypsin (Promega) at $35^{\circ} \mathrm{C}$ overnight (also at 1:50 ratio w/w). Digestion was stopped by the addition of $1 \%(\mathrm{v} / \mathrm{v})$ trifluoroacetic acid (TFA). Crosslinked peptides were enriched on a Superdex Peptide PC 3.2/30 column $(300 \times 3.2 \mathrm{~mm})$ at a flow rate of $25 \mu \mathrm{min}^{-1}$ and water/acetonitrile/TFA, 75:25:0.1 as a mobile phase. Fractions were analysed by liquid chromatography coupled to tandem mass spectrometry using a hybrid LTQ Orbitrap Elite (Thermo Scientific) instrument. Cross-linked peptides were identified using $x$ Quest ${ }^{9}$. False discovery rates (FDRs) were estimated by using $\mathrm{xProphet}^{10}$ and results were filtered according to the following parameters: FDR $=0.05$, min delta score $=0.85$, MS1 tolerance window of -4 to $4 \mathrm{ppm}$, ld-score $>22$. The crosslinks were visualised using the webserver $\mathrm{xVis}$ (http://xvis.genzentrum.lmu.de/) [reference $\left.{ }^{11}\right]$. 


\section{Extended Data Figure 1}

\section{Building blocks of the kinetochore}

Schematic organization of protein and sub-complexes used in this study, with essential structural features. CENP-A is a histone $\mathrm{H} 3$ variant. Crucial to its function in kinetochore assembly are the so-called CATD box and the C-terminal region, which are believed to interact with CENP-N and CENP-C, respectively ${ }^{12-14}$. CENP-C is a blueprint for kinetochore assembly, with binding motifs for outer and inner kinetochore subunits ordered from the $\mathrm{N}$ - to the $\mathrm{C}$-terminus. The $\mathrm{N}$-terminal region starts with a binding site for the Mis12 complex ${ }^{15,16}$, followed by a binding site for the CENP-HIKM complex ${ }^{6}$. Two related nucleosome-binding motif have been identified, in the so-called "central region" and "CENP-C motif" [reference ${ }^{13}$ ]. The nucleosome-binding motifs interact with the H2A:H2B dimer and with the C-terminal region of CENP-A ${ }^{13}$. Finally, the dimerization motif has a cupin-like fold ${ }^{17}$. The C-terminal region also binds to M18BP1 ${ }^{18,19}$, which is involved in CENP-A deposition. The two subunits of the CENPLN complex have similar size and are structurally related, as revealed by the crystal structure of their $S$. cerevisiae's homologs ${ }^{20}$. The 4-subunit CENP-HIKM complex contains a tight sub-complex of the CENP-H and CENP-K subunits ${ }^{6}$. CENP-M is a pseudo Ras-like small GTPase that has lost the ability to bind $\mathrm{GTP}^{6}$. It interact with CENP-I and is required for its stability ${ }^{6}$, but no CENP-M ortholog has been identified in S. cerevisiae, whereas Ctf3 is the CENP-I ortholog in this organism (see Figure 4a). Structurally, CENP-I may resemble the HEAT-repeat $\alpha$-solenoid structure of Importin$\beta$ [reference ${ }^{6}$ ]. The 4 -subunit Ndc80 complex is crucial for microtubule binding by kinetochores ${ }^{21,22}$. It is a dumbbell-shaped, elongated protein with large coiled-coil domains $^{23,24}$. Calponin-homology $(\mathrm{CH})$ domains near the $\mathrm{N}$-terminus of the $\mathrm{Ndc} 80$ and Nuf2 subunits have been implicated in microtubule binding ${ }^{23,24}$. The Spc24 and Spc25 subunits target the $\mathrm{Ndc} 80$ complex to the kinetochore ${ }^{25,26}$ through interactions with the Mis12 complex. The 4-subunit Mis12 complex remains structural uncharacterized, except for low resolution negative-stain electron microscopy analyses ${ }^{26-29}$. It is a hub of interactions, including interactions with the CENP-C complex (discussed above), the Ndc80 complex (also discussed above), and the Knl1 subunit of the Knl1 complex ${ }^{28}$. The 2-subunit Knl1 complex plays a crucial role in spindle assembly checkpoint signalling ${ }^{30}$. The C-terminal region of Knl1, the largest known core kinetochore subunits, consists of tandem RWD domains and is sufficient with an interaction with the Mis12 complex ${ }^{26,28}$. 
A longer region, approximately comprising the last 300 residues, is also sufficient for tight binding to Zwint. For our studies, we used a construct encompassing residues $\mathrm{Knl}^{2000-2311}$, and endowed with the ability to bind the Mis12 complex and Zwint.

\section{Extended Data Figure 2}

Size-exclusion chromatography analyses

The indicated samples (at a concentration of $10 \mu \mathrm{M}, 5 \mu \mathrm{M}$ for mononucleosomes) were loaded on the indicated size-exclusion chromatography column and the resulting elution fractions were analysed by SDS-PAGE. a, CENP-NL complex. b, CENP-C ${ }^{1-544}$ complex.

c, CENP-HIKM. d, KMN network. e, CENP-A ${ }^{\mathrm{MN}}$; the lower panel is a MidoriGreen stained agarose gel of the same fractions analysed by SDS-PAGE in the upper panel. $\mathbf{f}$, $\mathrm{H} 3^{\mathrm{MN}}$; lower panel as in $\mathbf{e}$.

\section{Extended Data Figure 3}

\section{Kinetochore localization studies}

Representative images showing kinetochore levels in interphase cells of CENP-A, CENP-C, and CENP-HK (with an antibody raised against the CENP-HK complex) in Flp-In T-REx HeLa cells upon treatment with the indicated siRNA. Kinetochores were visualized with anti-CENP-A sera. Scale bar $=10 \mu \mathrm{m}$. Magnification $=630 \mathrm{x}$.

\section{Extended Data Figure 4}

\section{Controls for fluorescent MT binding experiment}

a, Additional controls for the MT binding assays shown in Figure 3c. Rhodaminelabelled microtubules (red channel) were tethered to glass coverslips and incubated in the presence of GFP-KMN (green), Alexa-488 labelled CHIKLMN (blue), or Alexa-647 labelled CENP-A MN (purple), and combinations thereof. $\mathbf{b}$, only CENP-A ${ }^{\mathrm{MN}}$ were translocated to microtubules, whereas $\mathrm{H} 3^{\mathrm{MN}}$ were not. The upper panel was already shown in Figure 3c. 


\section{Extended Data Figure 5}

\section{Topology of the kinetochore}

Kinetochore topology. Using chemical cross-linking and mass spec the inter-peptide interactions within the kinetochore sample were analysed. Intra protein cross-links are shown in red, intra-subcomplex cross-links are shown in green, inter-subcomplex crosslinks in blue. Proteins are coloured according to sub-complex Proteins are coloured according to their sub-complex. CENP-A ${ }^{\mathrm{MN}}$, purple; CENP-C, red; CENP-HIKM, green; CENP-NL, blue; Mis12, peach; Knl1, orange; Ndc80, yellow.

\section{Extended Data Figure 6}

\section{CENP-C $C^{545-943}$ does not interact with $C C A N$ subunits}

a, SEC analysis of CENP-A ${ }^{\mathrm{MN}}$ (purple), CENP-C $\mathrm{C}^{631-943}$ (red trace), and their combination (green trace) shows a stoichiometric interaction. b, SEC analysis of CENP-NL (blue trace), CENP-HIKM (green trace), CENP-C ${ }^{545-943}$ (red trace), and their combination (orange trace). No apparent shift of CENP-C was observed.

\section{Extended Data Table I}

Table of cross-links identified by mass spectrometry on the CENP-A ${ }^{\mathrm{MN}}$ :CHIKLMN complex

\section{Extended Data Table II}

Table of cross-links identified by mass spectrometry on the CENP$\mathrm{A}^{\mathrm{MN}}$ :CHIKLMN:KMN complex 


\section{Extended data References}

1 Bieniossek, C., Imasaki, T., Takagi, Y. \& Berger, I. MultiBac: expanding the research toolbox for multiprotein complexes. Trends Biochem Sci 37, 49-57, doi:10.1016/j.tibs.2011.10.005 (2012).

2 Hashimoto, Y., Zhang, S., Zhang, S., Chen, Y. R. \& Blissard, G. W. Correction: BTI-Tnao38, a new cell line derived from Trichoplusia ni, is permissive for AcMNPV infection and produces high levels of recombinant proteins. BMC Biotechnol 12, 12, doi:10.1186/1472-6750-12-12 (2012).

3 Dyer, P. N. et al. Reconstitution of nucleosome core particles from recombinant histones and DNA. Methods Enzymol 375, 23-44 (2004).

4 Guse, A., Fuller, C. J. \& Straight, A. F. A cell-free system for functional centromere and kinetochore assembly. Nat Protoc 7, 1847-1869, doi:10.1038/nprot.2012.112 (2012).

5 Fujita, Y. et al. Priming of centromere for CENP-A recruitment by human hMis18alpha, hMis18beta, and M18BP1. Developmental cell 12, 17-30, doi:10.1016/j.devcel.2006.11.002 (2007).

6 Basilico, F. et al. The pseudo GTPase CENP-M drives human kinetochore assembly. Elife 3, e02978, doi:10.7554/eLife.02978 (2014).

7 Tighe, A., Johnson, V. L. \& Taylor, S. S. Truncating APC mutations have dominant effects on proliferation, spindle checkpoint control, survival and chromosome stability. J Cell Sci 117, 6339-6353, doi:10.1242/jcs.01556 (2004).

8 Trazzi, S. et al. The C-terminal domain of CENP-C displays multiple and critical functions for mammalian centromere formation. PLoS One 4, e5832, doi:10.1371/journal.pone.0005832 (2009).

9 Herzog, F. et al. Structural probing of a protein phosphatase 2A network by chemical cross-linking and mass spectrometry. Science 337, 1348-1352, doi:10.1126/science.1221483 (2012).

10 Walzthoeni, T. et al. False discovery rate estimation for cross-linked peptides identified by mass spectrometry. Nat Methods 9, 901-903, doi:10.1038/nmeth.2103 (2012).

11 Grimm, M., Zimniak, T., Kahraman, A. \& Herzog, F. xVis: a web server for the schematic visualization and interpretation of crosslink-derived spatial restraints. Nucleic Acids Res 43, W362-369, doi:10.1093/nar/gkv463 (2015).

12 Black, B. E. et al. Structural determinants for generating centromeric chromatin. Nature 430, 578-582, doi:10.1038/nature02766 (2004).

13 Kato, H. et al. A conserved mechanism for centromeric nucleosome recognition by centromere protein CENP-C. Science 340, 1110-1113, doi:10.1126/science.1235532 (2013). 
14 Carroll, C. W., Silva, M. C., Godek, K. M., Jansen, L. E. \& Straight, A. F. Centromere assembly requires the direct recognition of CENP-A nucleosomes by CENP-N. Nature cell biology 11, 896-902, doi:10.1038/ncb1899 (2009).

15 Przewloka, M. R. et al. CENP-C is a structural platform for kinetochore assembly. Current biology : CB 21, 399-405, doi:10.1016/j.cub.2011.02.005 (2011).

16 Screpanti, E. et al. Direct binding of Cenp-C to the Mis12 complex joins the inner and outer kinetochore. Current biology : CB 21, 391-398, doi:10.1016/j.cub.2010.12.039 (2011).

17 Cohen, R. L. et al. Structural and functional dissection of Mif2p, a conserved DNA-binding kinetochore protein. Molecular biology of the cell 19, 4480-4491, doi:10.1091/mbc.E08-03-0297 (2008).

18 Dambacher, S. et al. CENP-C facilitates the recruitment of M18BP1 to centromeric chromatin. Nucleus 3, 101-110, doi:10.4161/nucl.18955 (2012).

19 Milks, K. J., Moree, B. \& Straight, A. F. Dissection of CENP-C-directed centromere and kinetochore assembly. Molecular biology of the cell 20, 4246-4255, doi:10.1091/mbc.E09-05-0378 (2009).

20 Hinshaw, S. M. \& Harrison, S. C. An Iml3-Chl4 heterodimer links the core centromere to factors required for accurate chromosome segregation. Cell Rep 5, 29-36, doi:10.1016/j.celrep.2013.08.036 (2013).

21 Cheeseman, I. M., Chappie, J. S., Wilson-Kubalek, E. M. \& Desai, A. The conserved KMN network constitutes the core microtubule-binding site of the kinetochore. Cell 127, 983-997, doi:10.1016/j.cell.2006.09.039 (2006).

22 DeLuca, J. G. et al. Kinetochore microtubule dynamics and attachment stability are regulated by Hec1. Cell 127, 969-982, doi:10.1016/j.cell.2006.09.047 (2006).

23 Ciferri, C. et al. Implications for kinetochore-microtubule attachment from the structure of an engineered Ndc80 complex. Cell 133, 427-439, doi:10.1016/j.cell.2008.03.020 (2008).

24 Wei, R. R., Al-Bassam, J. \& Harrison, S. C. The Ndc80/HEC1 complex is a contact point for kinetochore-microtubule attachment. Nature structural \& molecular biology 14, 54-59, doi:10.1038/nsmb1186 (2007).

25 Kiyomitsu, T., Iwasaki, O., Obuse, C. \& Yanagida, M. Inner centromere formation requires hMis14, a trident kinetochore protein that specifically recruits HP1 to human chromosomes. The Journal of cell biology 188, 791-807, doi:10.1083/jcb.200908096 (2010).

26 Petrovic, A. et al. Modular assembly of RWD domains on the Mis12 complex underlies outer kinetochore organization. Molecular cell 53, 591-605, doi:10.1016/j.molcel.2014.01.019 (2014).

27 Hornung, P. et al. Molecular architecture and connectivity of the budding yeast Mtw1 kinetochore complex. J Mol Biol 405, 548-559, doi:10.1016/j.jmb.2010.11.012 (2011). 
28 Petrovic, A. et al. The MIS12 complex is a protein interaction hub for outer kinetochore assembly. The Journal of cell biology 190, 835-852, doi:10.1083/jcb.201002070 (2010).

29 Maskell, D. P., Hu, X. W. \& Singleton, M. R. Molecular architecture and assembly of the yeast kinetochore MIND complex. The Journal of cell biology 190, 823-834, doi:10.1083/jcb.201002059 (2010).

30 Ghongane, P., Kapanidou, M., Asghar, A., Elowe, S. \& Bolanos-Garcia, V. M. The dynamic protein Knl1 - a kinetochore rendezvous. Journal of cell science 127, 3415-3423, doi:10.1242/jcs.149922 (2014). 


\begin{tabular}{|c|c|c|c|c|}
\hline CENP-A & Hs CENP-M & 140 & $\square$ CATD & [C-TERM \\
\hline Q $\begin{array}{c}\text { CENP } \\
\text { nucleos }\end{array}$ & & 0 & $\begin{array}{l}\text { 75-CVKFTRGVDFNWQAQALLALQ } \\
\text { EAAEAFLVHLFEDAYLLTLHA-116 }\end{array}$ & 134-CVKFTRG-140 \\
\hline
\end{tabular}

Nucleosome-binding motifs

H. Sapiens 516-TVTKSRRISRRPSDWWVVKSEE-537

H. Sapiens 736-NVRRTKRTRLKPLEYWRGERIDY-758

X. laevis 568-TVTKSRRISRRPSDWWVVKSEE-537 $X$. laevis 1204 -NVRRSKRTRVKPLAYWKGERVNY-1226

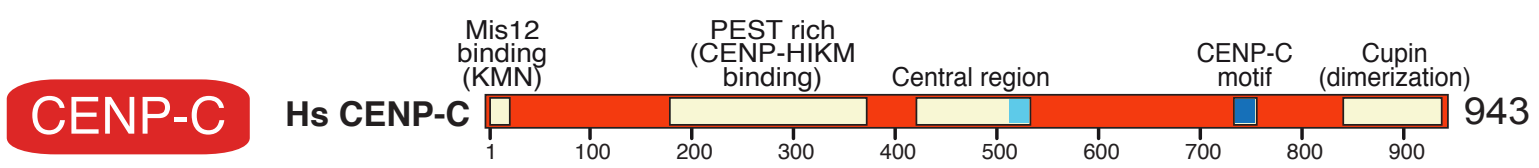

\section{CENP-L CENP-N}

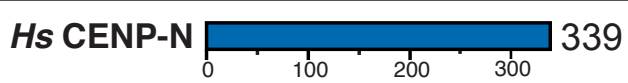

Hs CENP-L
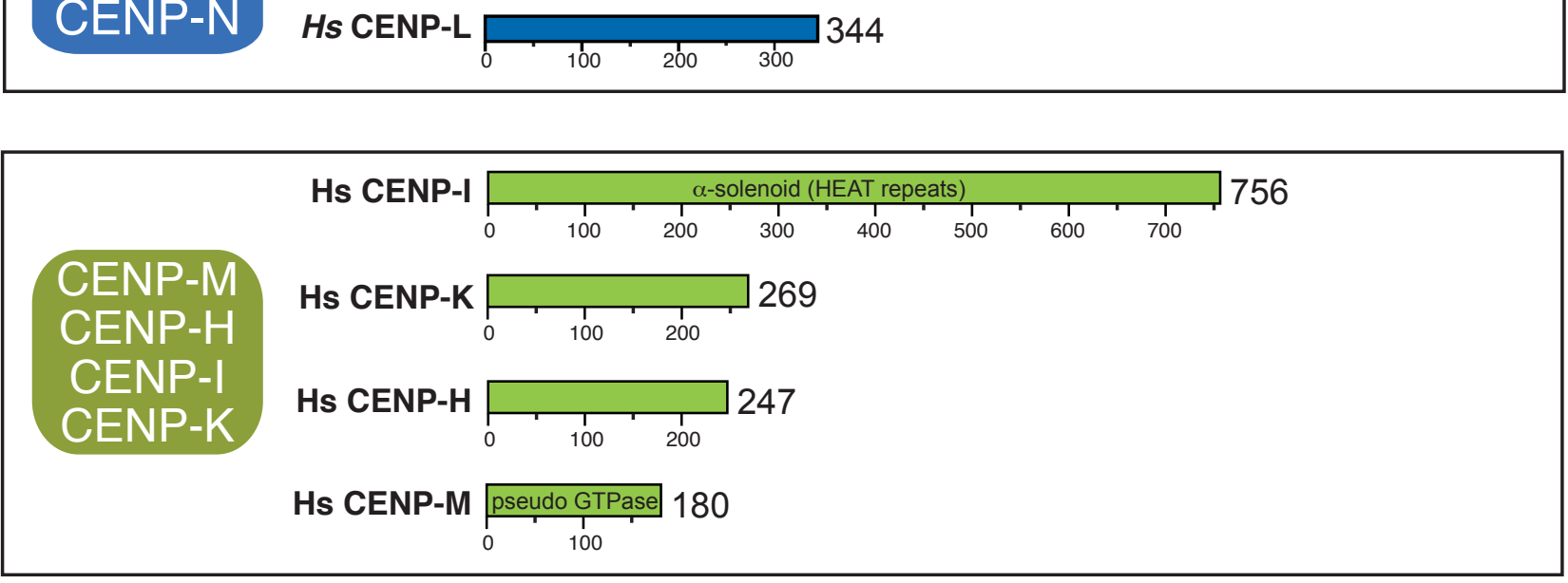

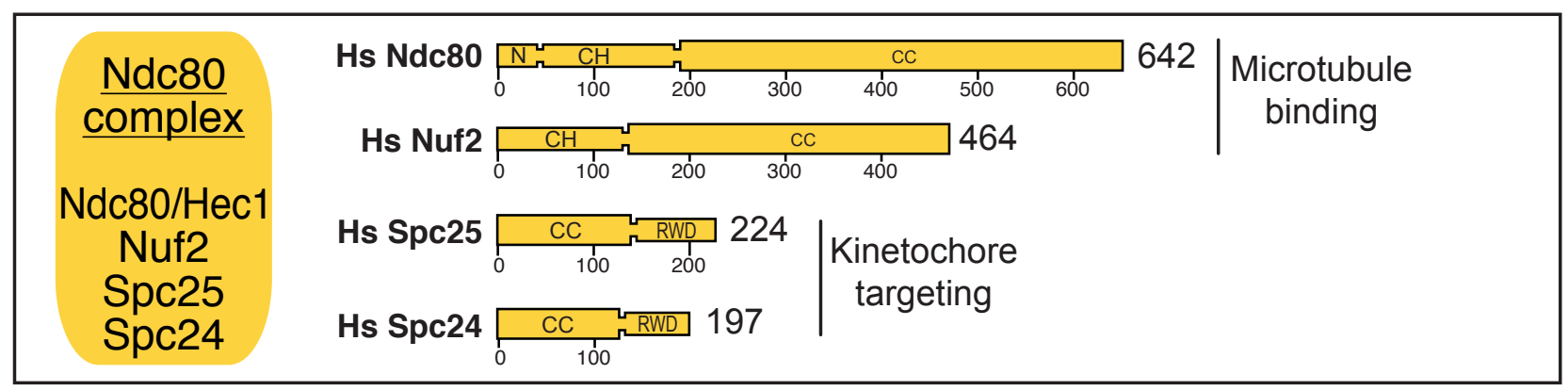

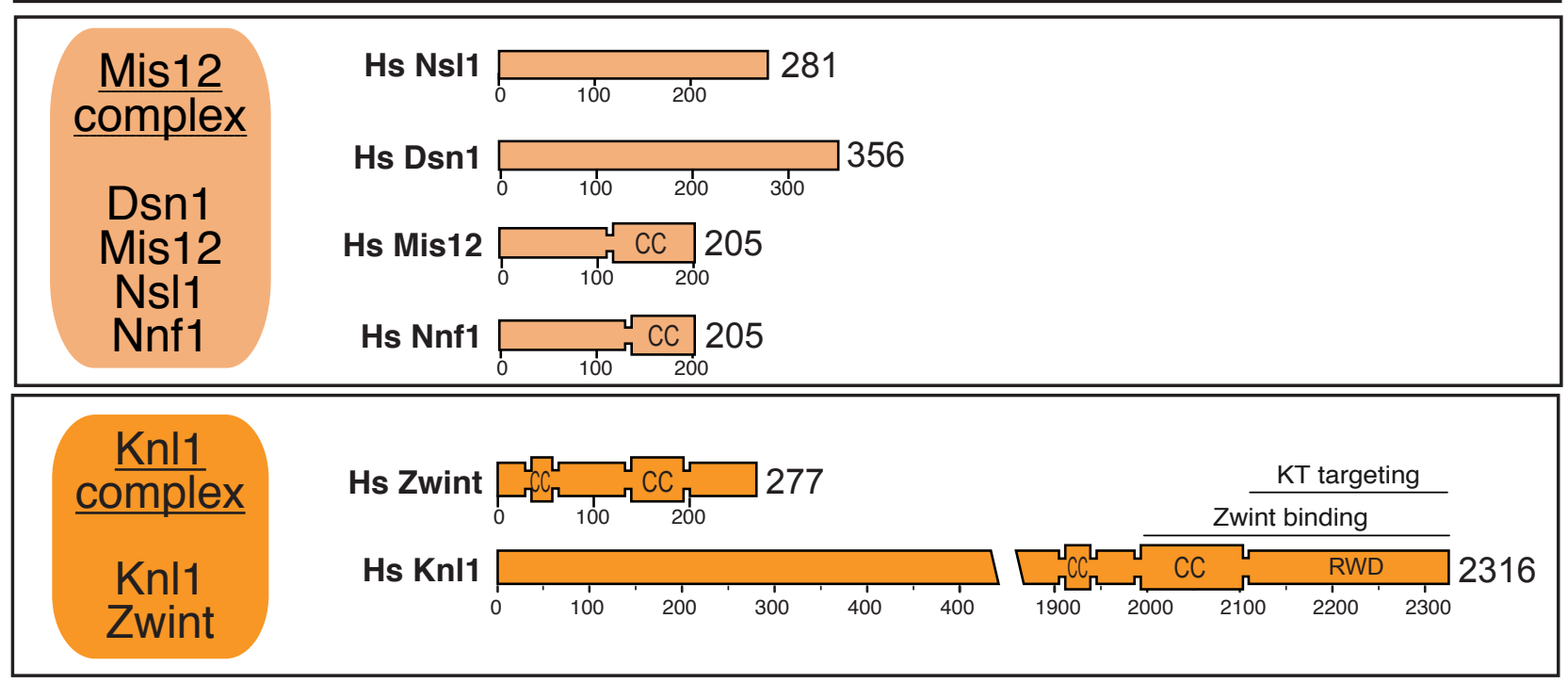



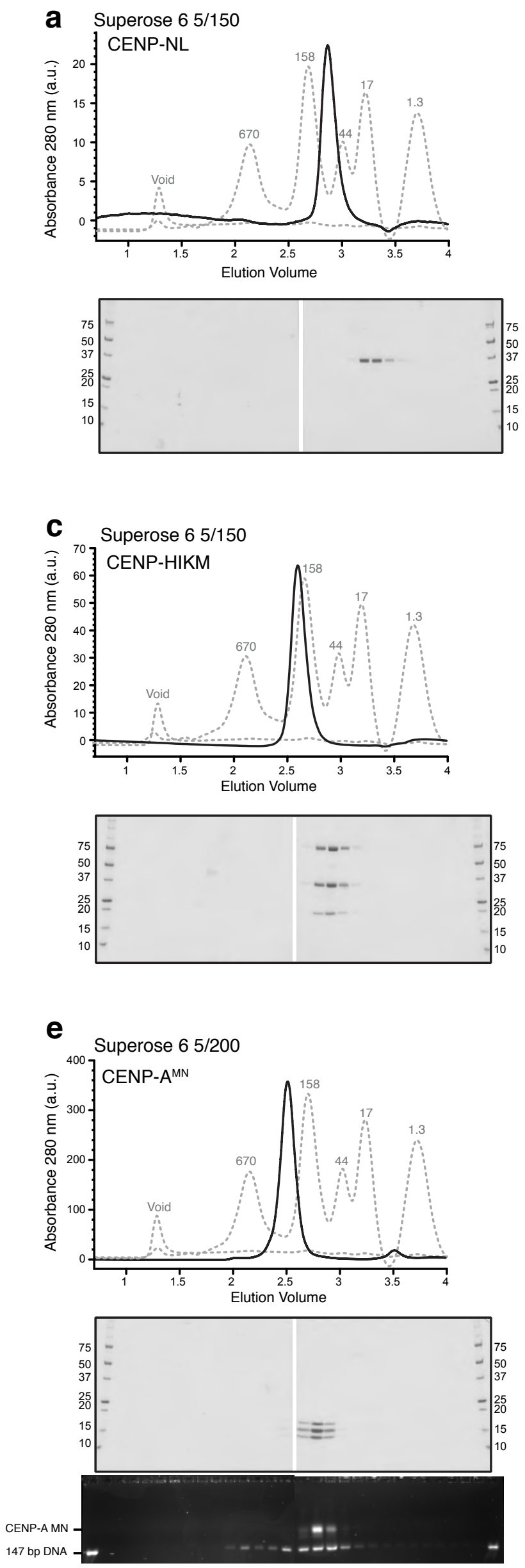

b
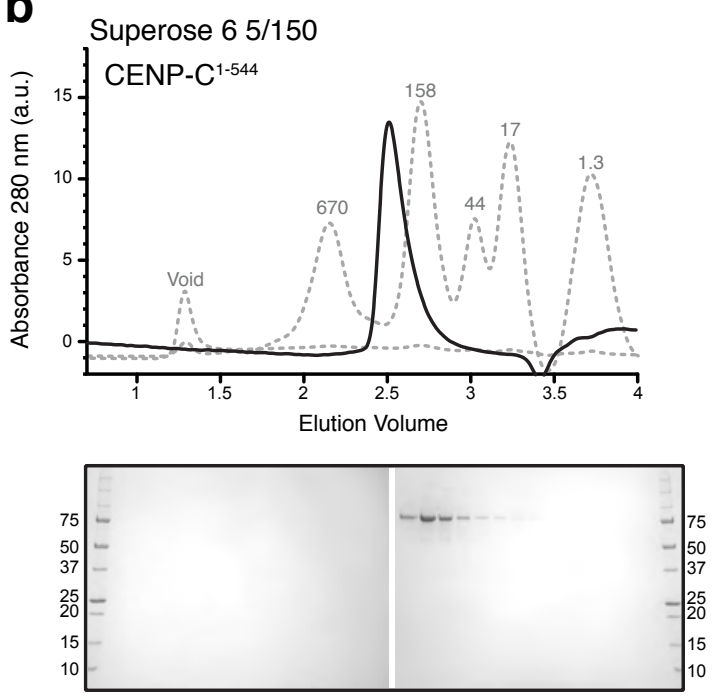

\section{d}
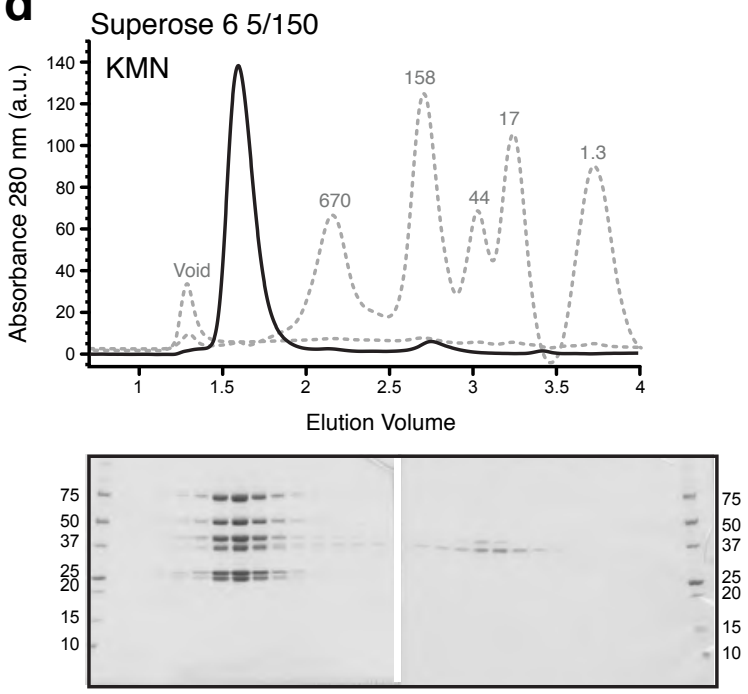

f Superose 6 5/150
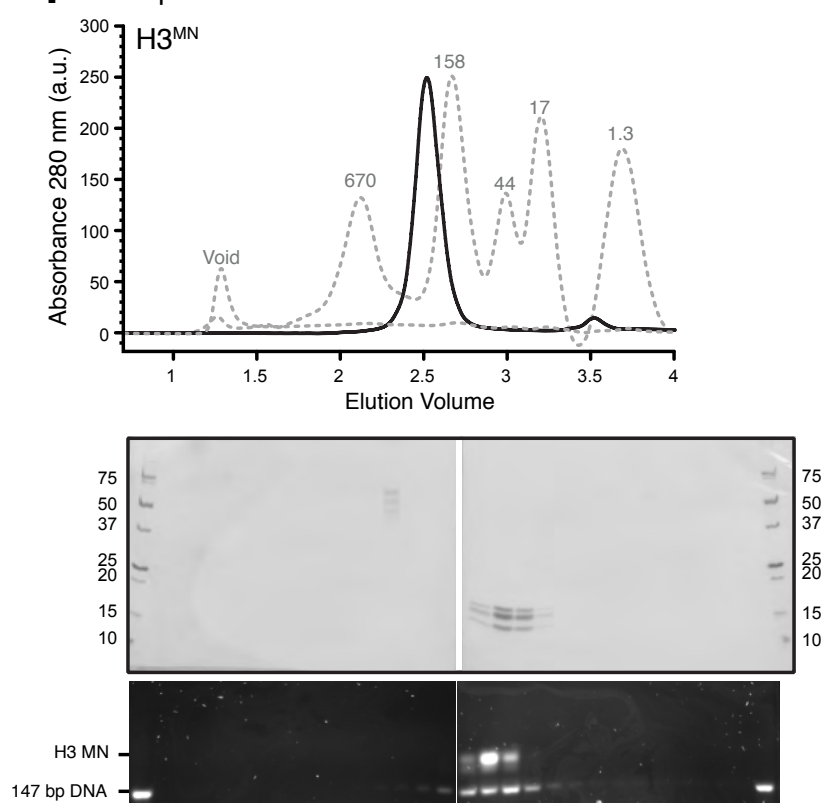


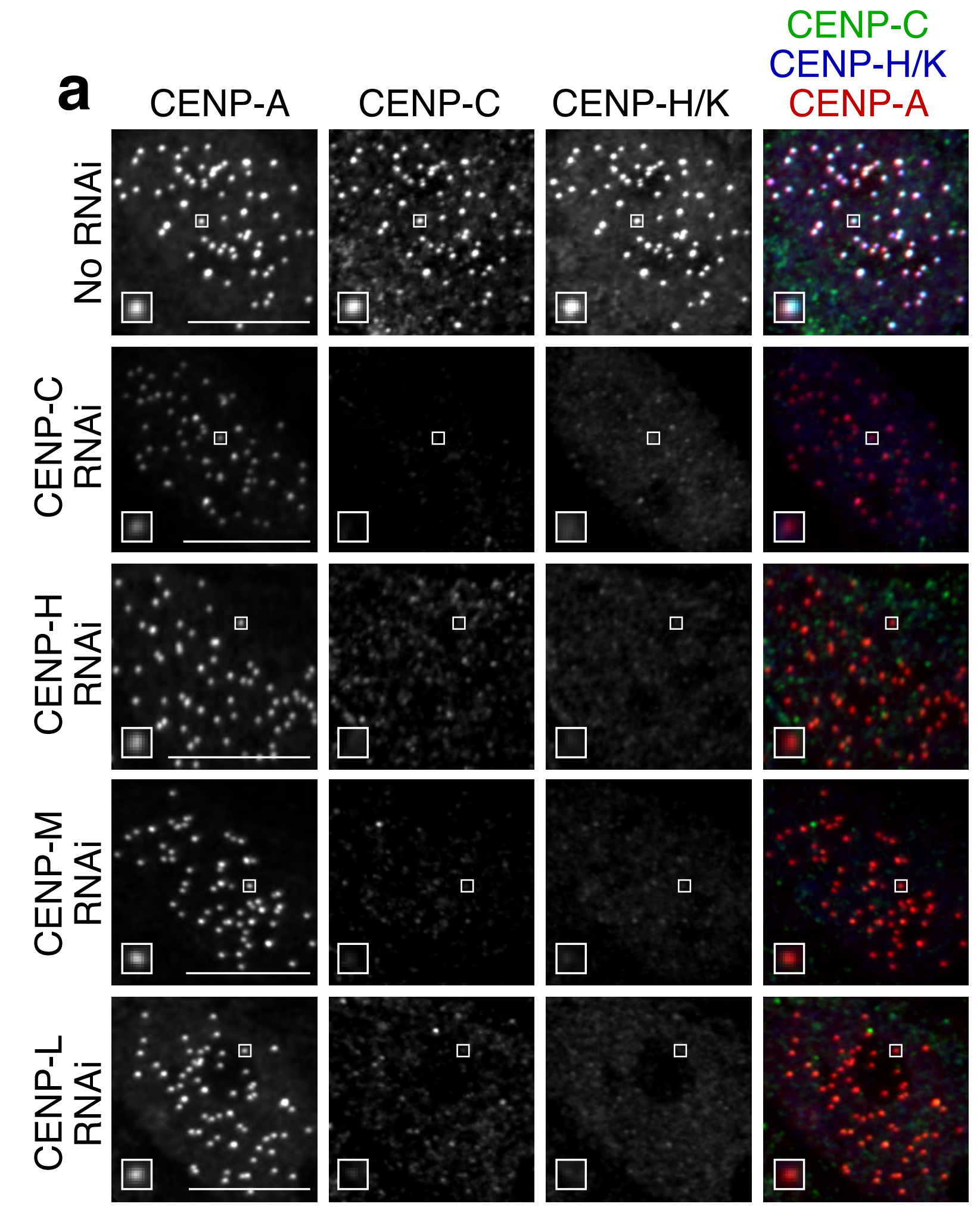

Western blot depletion control goes here 
a

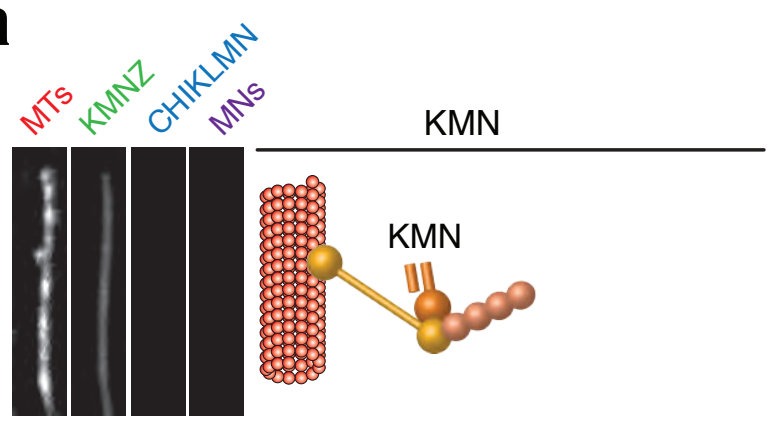

$\mathrm{KMN}+\mathrm{CENP}-\mathrm{A}^{\mathrm{MN}}$
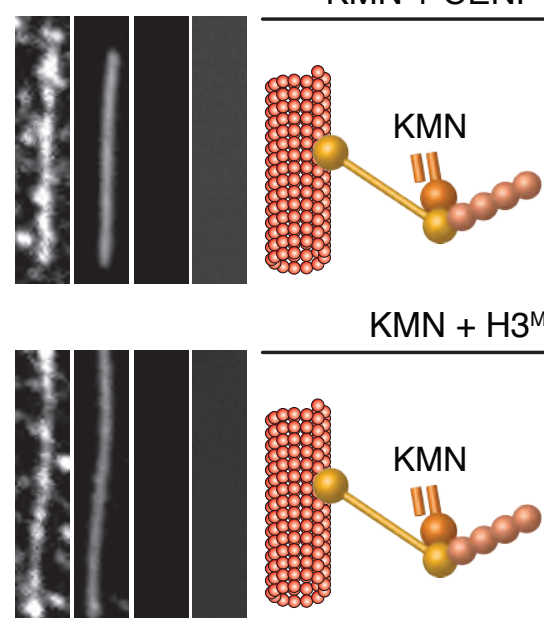

b
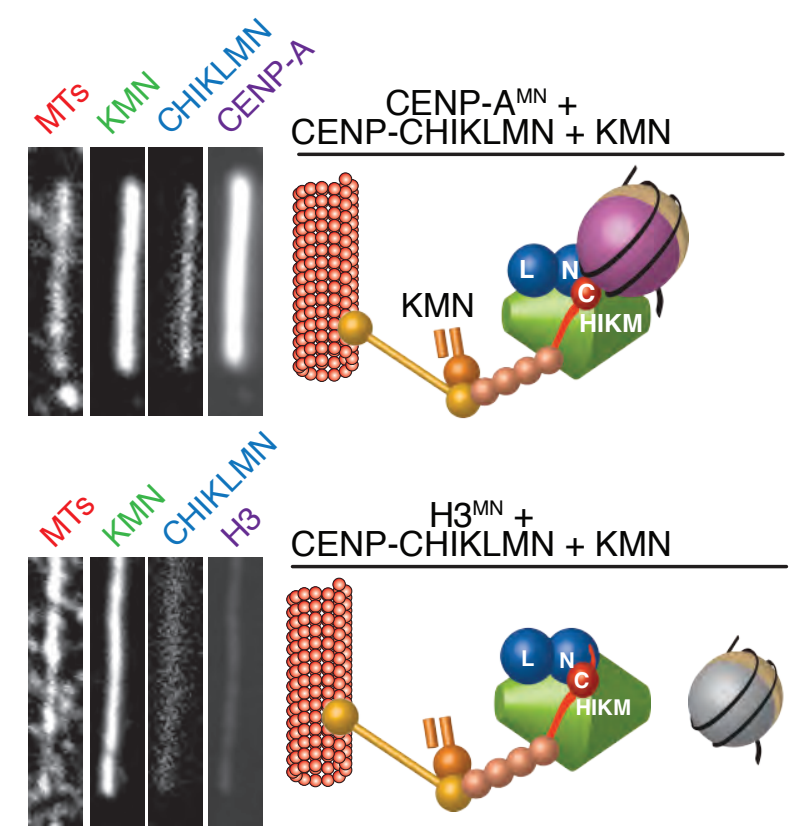
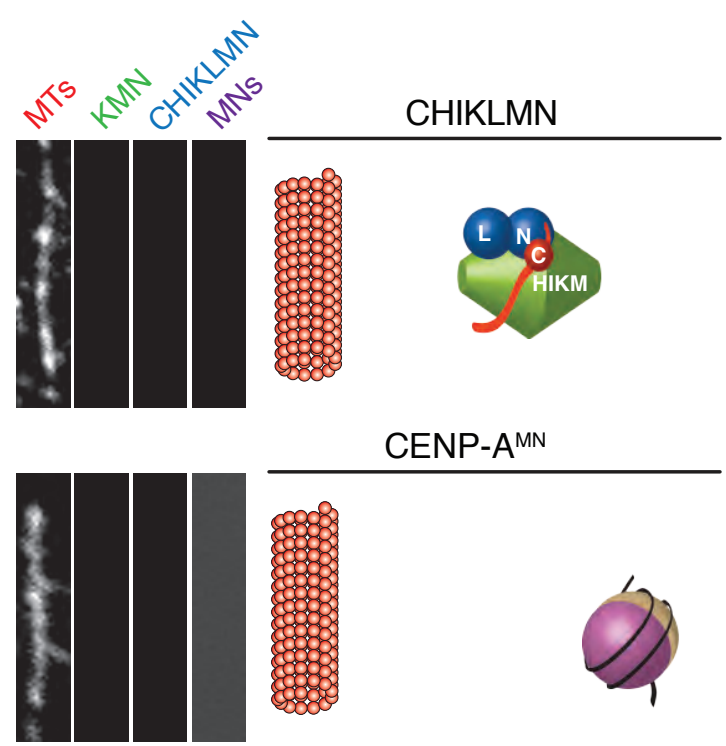

CENP-A ${ }^{\mathrm{MN}}$

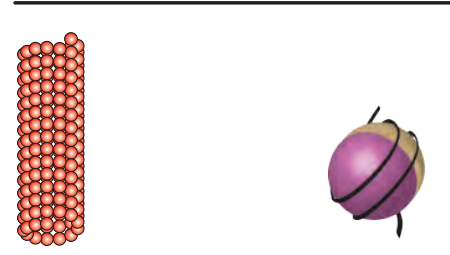

$H 3^{\mathrm{MN}}$
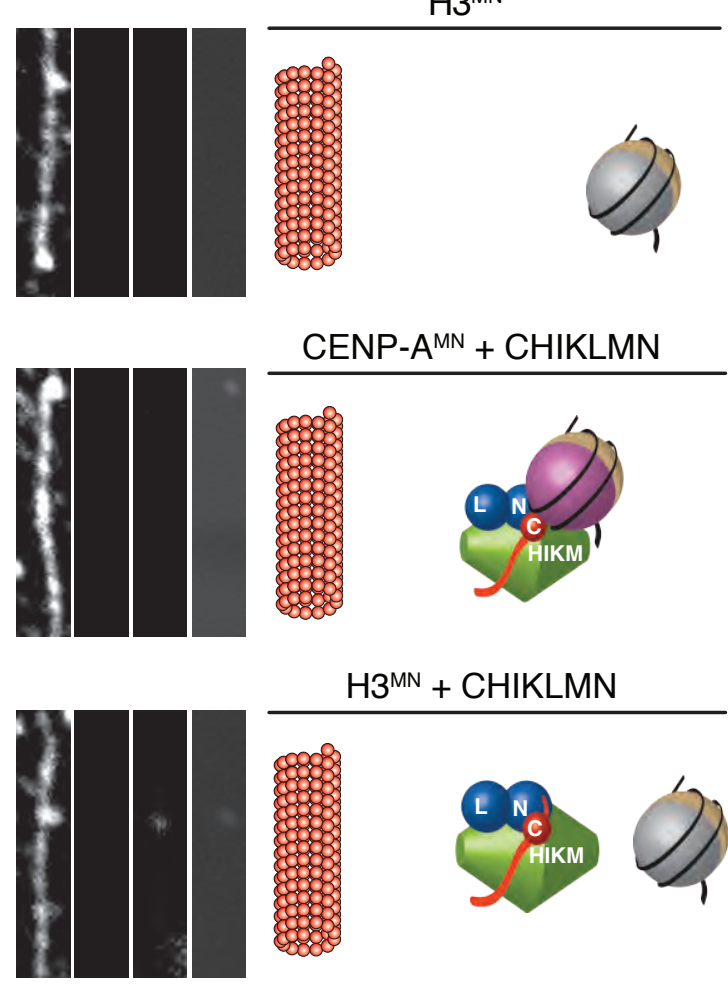

Weir et al.

Extended Figure 5 


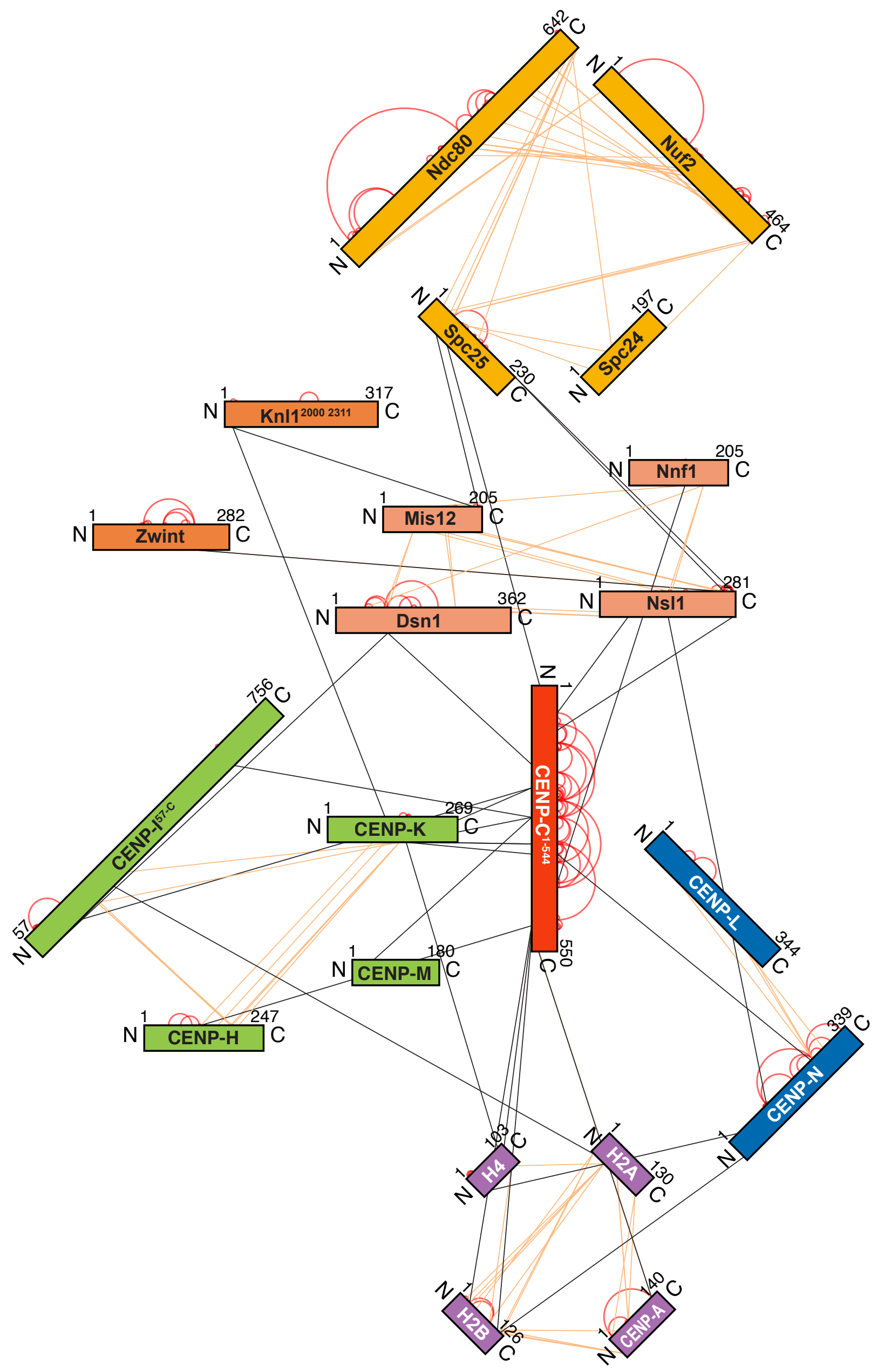

Weir et al.

Extended Figure 4 
Superdex 200 5/150 INCREASE

CENP-NL

CENP-HIKM

CENP-C ${ }^{545-943}$
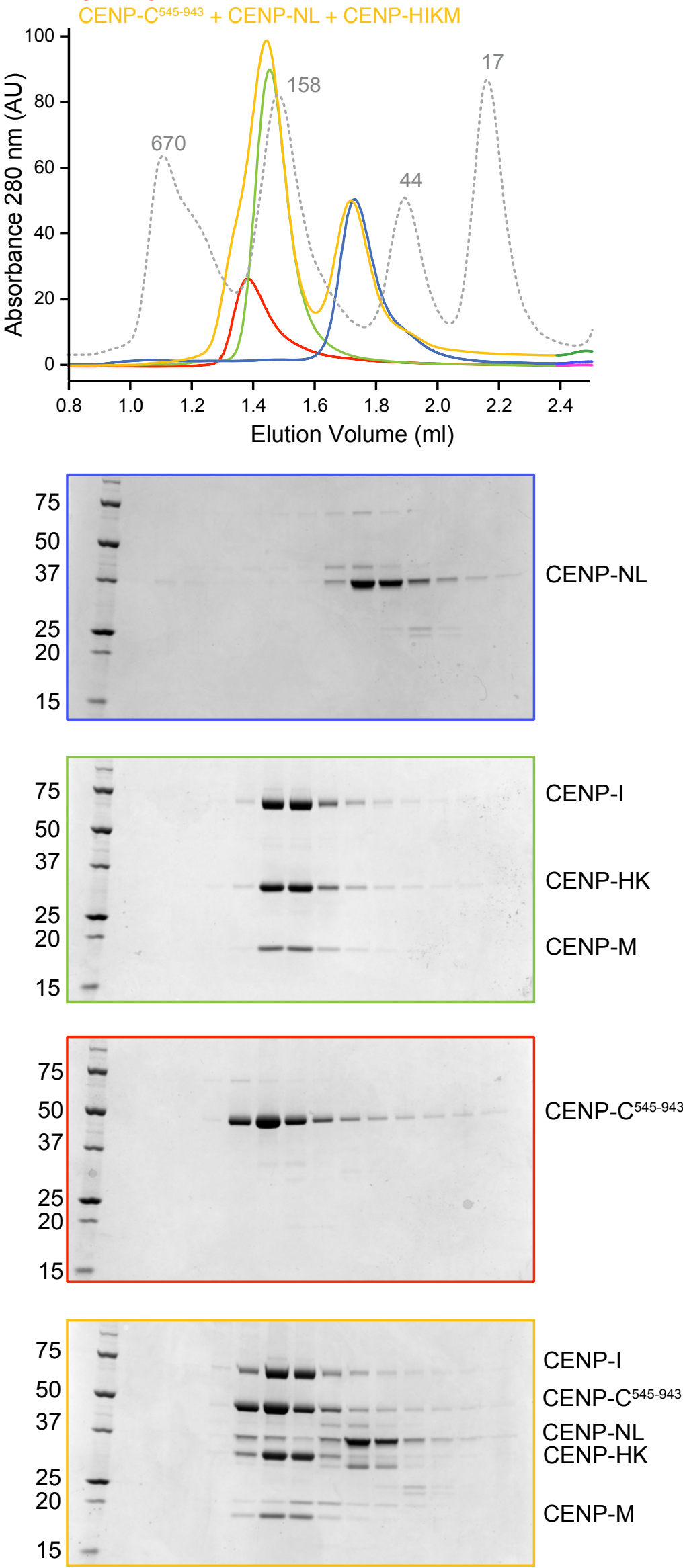

Weir et al.

Extended Figure 6 


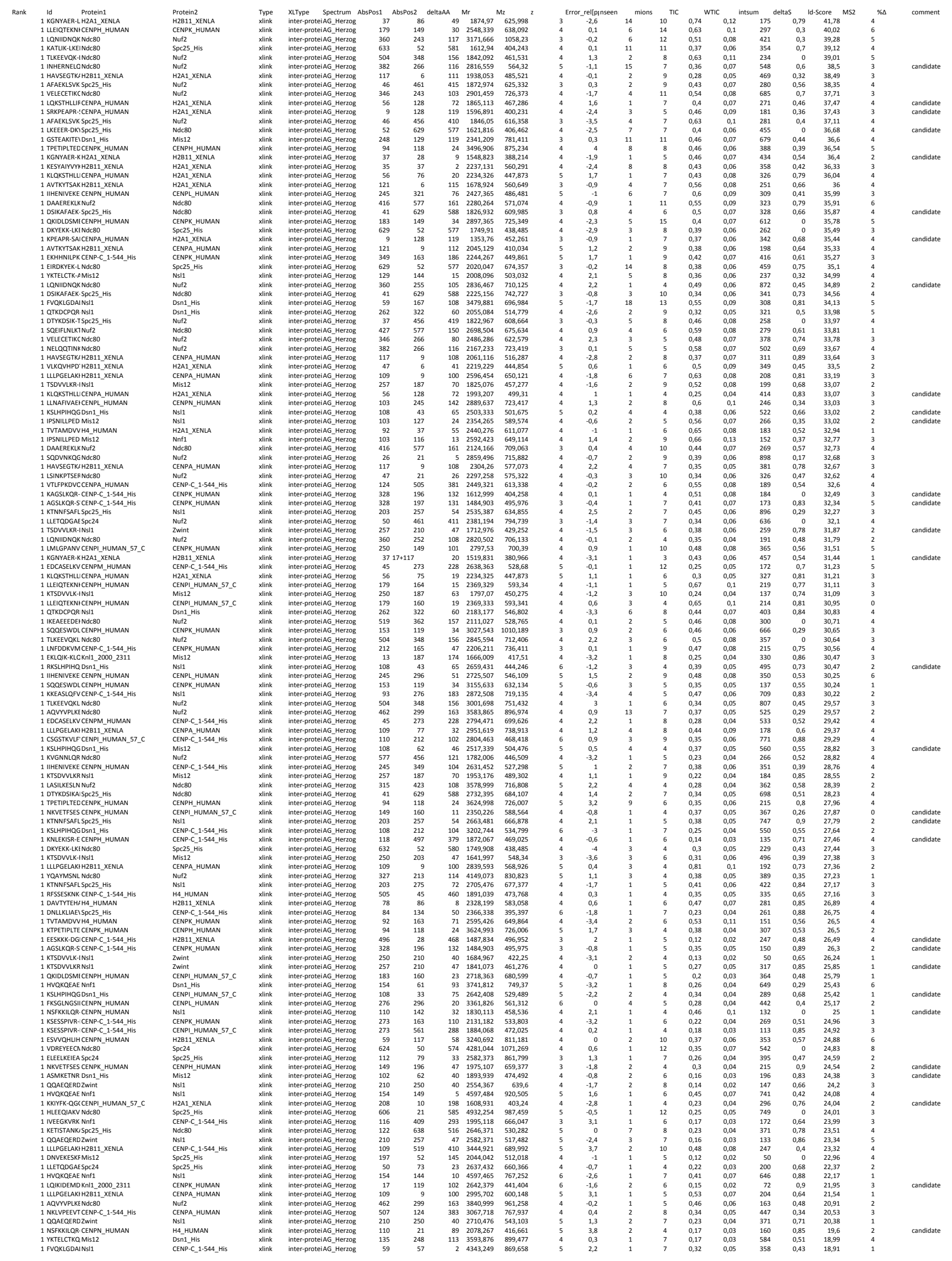




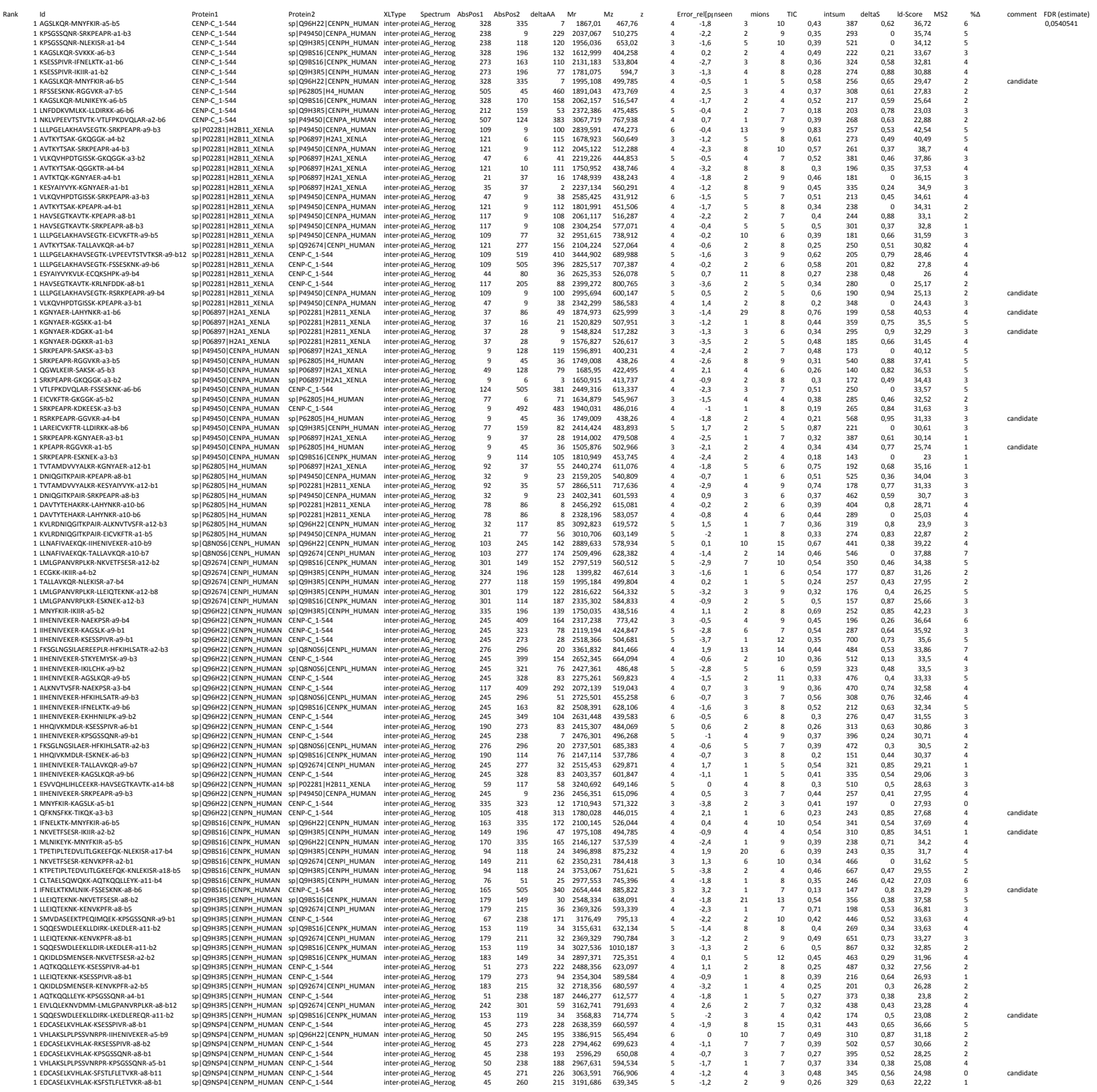

